\title{
Effect of Concrete Slab on the Behavior of Fire Exposed Subframe Assemblies with Bolted Double Angle Connections
}

\author{
Purushotham Pakala ${ }^{1}$, Venkatesh Kodur ${ }^{2}$
}

\begin{abstract}
:
This paper presents the development of a three-dimensional nonlinear finite element model for evaluating the system-level transient fire response of double angle connections that are part of a sub framed assembly. The behavior of two subframe assemblies, with double angle connections, exposed to different fire scenarios were modeled using a commercially available finite element software ANSYS. The finite element model accounts for material and geometrical nonlinearities, degradation of constitutive material properties with temperature and non-linear contact interactions. The model is validated by comparing predicted thermal and structural response parameters of connection assemblies with measured data from fire tests on subframe assemblies with and without the concrete slab. The validated model is applied to study the effect of decay rate, loading type, presence of the concrete slab and degree of axial restraint on the fire performance of double angle connection assemblies. Results from the parametric studies indicate that decay rate, loading type and axial restraint have significant influence on the transient fire performance of subframe assembly. Further, presence of the concrete slab significantly enhances the rigidity of the connection assembly and mitigates local instabilities, such as local and lateral torsional buckling, that arise in beams and this improves the performance of connections.
\end{abstract}

Keywords: Double angle connections, web cleat, transient fire response, sub-frame assembly, steel angle connections, fire behavior of connections

\section{INTRODUCTION}

Steel framed systems are frequently used in high-rise buildings. In these steel framed structures, connections play a significant role in transferring forces from one structural member to another

\footnotetext{
${ }^{1}$ Purushotham Pakala,

Formerly Ph.D. Candidate, Dept. of Civil and Environmental Engg., Michigan State University, East Lansing, MI 48823.

${ }^{2}$ Venkatesh Kodur,

Professor, Dept. of Civil and Environmental Engg., Michigan State University, East Lansing, MI 48823 (corresponding author) E-mail: kodur@egr.msu.edu (V.Kodur), Tel: +1 5173539813.
} 
member and influence the overall stability of the structural system at ambient and fire conditions. Performance of connections is much more crucial under fire conditions as they experience degradation in load carrying capacity and stiffness, due to deterioration of strength and elastic modulus of steel with temperature. Results from full-scale fire tests indicate that connections performance can significantly affect the failure time of structural members exposed to fire due to their ability in transferring forces [1-3]. Therefore, it is vital to understand the behavior and performance of connections under fire conditions in order to predict the true response of the structural framing system.

Though various shear angle connection configurations exist, double angle connections are finding increasing applications. This is due to their superior tying resistance and rotational capacity compared to other less ductile connection types such as shear tab and end-plate. In traditional design, double angle shear connections are designed to resist shear forces that are generated from gravity (dead and live) and lateral wind loads. However, when a structural frame is subjected to fire conditions, connections experience additional fire induced forces (both tensile \& compressive) because of the axial restraint provided by the adjacent cold structural members. Though double angle connections are not designed to carry such axial loads they can sustain these additional forces by undergoing significant ductile deformation before failure $[4,5]$.

In a typical steel frame building, double angle connections form part of framing system along with the connected beams, columns and concrete slab. The presence of slab can have significant influence on fire performance of connections due to these factors (a) high thermal capacity of concrete enables the slab to act as heat sink which decreases the rate of temperature rise in both the beams and connections, (b) concrete slab offers lateral support (lateral bracing) to the connected beam and helps in stabilizing the beam from local and lateral torsional buckling instabilities. Previous studies on beam-slab assemblies show that the presence of the concrete slab can decrease connection temperatures anywhere in $12 \%$ - $38 \%$ range $[6,7]$ as compared to the beam lower flange temperature (at mid-span). In addition, the composite action provided by the slab helps in enhancing the fire performance (axial, flexural and shear) of beam-slab assemblies. However these factors were not accounted for modeling the behavior of full-scale connection assemblies. 
Fire design specifications for structural members, specified in prescriptive-based codes, are derived based on standard fire resistance tests. However, currently there are no standard specifications for testing connections that are an integral part of the structural framing system. Data available (in literature) on characterizing the fire response of connections indicates that currently the behavior of connection is assessed by testing isolated connections without taking into account the effect of the slab and transient temperature conditions. On the contrary, the true fire behavior of connection assemblies depends on structural continuity, nature and magnitude of fire induced forces, interactions between adjacent structural members, effect of the slab, thermal and mechanical properties of the connection components. All of these factors vary as a function of temperature. The influence of these parameters on the response of connections and overall structural frame cannot be captured when connections are tested in isolation $[8,9]$.

A review of literature indicates that there have been a number of numerical studies to model the fire performance of different types of connections. The most notable studies on connections are those by Liu [10], El-Houssieny et al. [11], Al-Jabri et al.[2], Daryan et al.[12], Azizinamini [13], Saedi [14], Saedi and Yahyai [15], Mao et al.[16], Garlock and Selamet [17-19] and Pakala et al. [4, 20]. These studies developed models for connections, using finite element computer programs such as ANSYS or ABAQUS, and studied the effect of connection flexibility, moment-rotation-stiffness characteristics, moment continuity, catenary tension forces and fire insulation on the fire behavior of connections. These finite element models accounted for material nonlinearity, friction, and temperature dependent stress-strain relations for steel. However, almost all of these studies focused either on isolated or scaled connections subjected to standard fire exposure and uniform temperature (steady-state) conditions without any consideration to the presence of the slab, natural fire with a cooling phase, realistic loading and restraint conditions. Further, most of these studies focused on end-plate connections (such as extended end-plate, flush end-plate, and flexible end-plate) while only limited studies focused on bolted angle and simple shear tab connections. Very few numerical studies focused on simple shear tab [21] connections or on the system-level response of double angle connections [4, 20]. This clearly indicates that there is a lack of data on the transient fire performance of double angle connections assemblies. 
To overcome some of the current drawbacks and to characterize the fire performance of double angle connection assemblies, numerical studies are carried out using commercially available software (ANSYS). Two steel-framed double angle connection assemblies, one with the concrete slab and the other without the concrete slab, are modeled under varying fire and loading conditions. The developed models are validated by comparing temperatures and deflections obtained from the numerical simulations with those measured in fire tests. The validated model is applied to evaluate the effect of the presence of concrete slab, fire scenario, axial restraint and type of loading on the fire performance of double angle connections.

\section{FINITE ELEMENT MODEL}

The analysis of beam-to-column double angle connection was carried out using ANSYS Parametric Design Language (APDL) code. ANSYS was selected because it is capable of handling highly non-linear thermal, structural and contact problems, while different geometric configurations and material models can be defined as parameters in APDL. Thus, the time required to create new models and conducting parametric studies can be done very easily by modifying values of influencing parameters in APDL. Geometric and material nonlinearities, high-temperature constitutive relationships and the contact interactions were incorporated in the analysis. It is important to note that many contact pairs exist in the connection region (such as bolt shank and bolt hole, angle and beam web, angle and column flange, bolt head/nut and angle, angle and column web etc.) and the behavior of these contact pairs has to be properly accounted for using appropriate contact interaction models [4]. However, incorporating contact behavior involves significant complexity and computational time which increases nonlinearly with each additional contact pair. After numerous initial trial runs, these complex contact interactions were successfully incorporated into the model using contact elements through surface-to-surface contact interaction model available in ANSYS [22]. Coulumb's frictional law was used to model the frictional forces [22] between beam, bolts, angles and column.

Fire resistance analysis was carried out by exposing a three-dimensional sub-frame assembly to different design fire scenarios. A finite element model was developed using ANSYS and the analysis was carried out using two sub-models namely thermal and structural model. In the thermal model, the structural frame was subjected to different fire exposure conditions and a transient thermal-stress analysis was carried out. The thermal model generates temperature 
distribution in the steel members subjected to fire scenario and this temperature distribution was applied as an input thermal body-load force in the structural sub-model and a stress analysis was performed. Detailed description of the thermal and structural models, contact interactions and high-temperature material models are presented in the following sections.

\subsection{Thermal model}

To study the transient fire performance of double angle connections, two tested sub-frame assemblies with double angle connections, designated as S1 and S2 [23], were selected. The layout of tested beam assemblies is shown in Fig. 1, while the connection details are illustrated in Fig. 2. Test set-up of the connection assemblies $\mathrm{S} 1$ and $\mathrm{S} 2$ is shown in Fig. 3 and Fig. 4, respectively. Test assembly S1 did not have a slab while assembly S2 had a slab. Since the geometry of the sub-frame assembly is symmetrical about two vertical planes, only one quarter of the geometry was modeled, as shown in Fig. 5.

The thermal analysis was conducted by discretizing the geometry with two types of elements, namely SOLID70 and SURF152 elements [24]. Both the steel and fire protection is modeled using SOLID70 elements. SOLID70 has three-dimensional thermal conduction capability and this element has eight nodes with a single degree of freedom, temperature, at each node. The element is applicable to a three-dimensional, steady-state or transient thermal analysis. SURF152 element is generally used for various load and surface effect applications [24]. In this study, SURF152 element was overlaid onto the face of SOLID70 3D thermal solid element (representing fire protection material) to simulate the effect of both thermal radiation and heat convection from ambient air to the fire exposed boundaries of the steel section.

In the model, a convective heat transfer coefficient of $25 \mathrm{~W} / \mathrm{m}^{2} \mathrm{~K}$ was used for fire exposed boundaries and $9 \mathrm{~W} / \mathrm{m}^{2} \mathrm{~K}$ was used for non-exposed boundaries [25]. Similarly a steel emissivity factor of 0.7 specified in Eurocode [6] is assumed in the analysis.

\subsection{Structural model}

For structural analyses, the geometry of the connection assembly was discretized using SOLID185 elements, suited for 3-D modeling of solid structures [24]. This SOLID185 element has eight nodes with three degrees of freedom at each node, namely translations in the nodal $x, y$ and $\mathrm{z}$ directions. This element has the capability of representing plasticity, stress stiffening, large 
deflections, large strains, material and geometrical nonlinearities. In order to accurately capture thermal and structural stress concentration in the connection region (angles, bolts, bolt holes), a relatively finer mesh was used within the vicinity of these regions.

The boundary conditions of the sub-frame assemblies were chosen so as to simulate the conditions present in actual fire test [23]. During the fire test, the test specimen was placed in the furnace such that only secondary beams were inside the furnace. The perimeter and parallel beams were fully outside the heating chamber of the furnace with perimeter beams resting on the cantilever supports, while the parallel beams were unsupported as shown in Fig. 1. During the fire test, to prevent the rotation of the assembly, pieces of wood were inserted between the perimeter beam and the furnace external frame. To simulate these test conditions in the finite element model, the stiffener present on the perimeter beam was modeled as fully fixed.

The connections at the end of secondary beams were outside of the furnace walls and were exposed to some heating indirectly through conduction from secondary beams and also from some level of radiation from the furnace walls. The connections were partially heated because of the fact that in buildings, connection regions are often embedded in walls and thus are not directly exposed to fire conditions.

Partially heated or unheated connections represent a worst-case scenario from fire perspective compared to connections that are fully heated. This is due to the fact that steel connections lose their load-carrying capacity with increase in temperature. Therefore, according to law of conservation of energy, for a given elevated temperature in order to obtain the same amount of energy (as that at room temperature) the displacement at failure should increase. This implies that the ductility increases with temperature as compared to that at room-temperature. An increased ductility alleviates forces in connections (and this becomes significant especially during the later stages of fire) thus delaying the failure time of connections and improving the overall fire response of sub-assemblies. Hence partially heated or unheated heated connections will have an earlier failure time compared to fully heated connections.

In assembly S2, the concrete slab was attached to the secondary beam using shear studs and was not restrained in any direction during the fire test. In the current model, shear studs are not modeled explicitly to avoid the need for defining and accounting for additional contact interactions associated with studs. However, the beam-slab composite action is accounted for 
indirectly by modeling surface-to-surface contact interactions between top flange of the beam and bottom most layer of the concrete slab. These contact interactions will ensure shear forces (which is the primary mechanism of force transfer in composite action) are effectively transferred at the interface of beam-slab. No restraining boundary conditions were applied to the concrete slab to simulate the conditions present in actual fire test.

The bolt shank, heads and nuts were modeled as circular volumes and the tapering between the angle legs, beam/column web and flange are ignored in the model. The bolt holes were assumed to be $2 \mathrm{~mm}$ oversize in comparison to the diameter of bolt shanks. The gap between different connection components (such as bolt head/nut and angle etc.) is assumed to be $0.1 \mathrm{~mm}$. To accurately capture stress concentrations around the bolts, bolt holes and angles, where failure is likely to be initiated, a relatively finer mesh was used in the vicinity of these regions.

\subsection{Contact interactions}

In a steel framed assembly, contact interactions exist between different components such as bolt shank and bolt hole, angle and beam/column web, bolt head/nut to the angle. Accounting for these contact interactions in analysis is quite complex because of the large number of interacting surfaces (parts) involved, highly nonlinear nature and large computational time. Additionally, selecting a surface as contact or target surface prior to the analysis is often unclear in most cases and numerous trial runs are needed to ensure that an appropriate contact surface area (either target or contact) has been selected.

To add further complexity, the behavior of interacting surfaces is highly dynamic because the surfaces can move in and out of contact regions within an iteration or between iterations [22]. This often creates numerical convergence problems due to sudden change in stiffness matrix and more equilibrium iterations (often with decreasing time step) have to be carried out to achieve convergence. Thus, the computational time for structural analyses with contact elements is generally higher than those without contact elements. Further, the computational time increases nonlinearly with each additional pair of interacting surfaces. This is due to the fact that an an time step, if equilibrium conditions are not satisfied even for one contact pair the iterations for all the contact pairs are repeated with a reduced time step. There are one hundred and seventeen contact pairs defined in the current model with approximately 42,113 contact elements. 
The contact interactions between different parts are defined using "contact pairs" and are modeled as "surface-to-surface" contact using contact elements CONTA174 and TARGE170 [24]. CONTA174 was used as a surface element and was overlaid on the underlying SOLID185 elements. The element is capable of three-dimensional structural and coupled field contact analyses. The element has eight nodes and is capable of modeling three-dimensional surface-tosurface contact interactions.

The three-dimensional contact surface elements (CONTA174) are associated with corresponding three-dimensional target segment elements (TARGE170) using a set of parameters referred to as real constant set. In ANSYS, contact can happen only between CONTA174 and TARG170 elements with the same set of real constants. Thus, the problem of spurious contact between contact elements in different "contact pairs" is taken care of.

Previous studies have shown that proper selection of contact pair parameters (contact algorithm, contact surface behavior, key options, real constant set) are crucial for avoiding most numerical convergence issues. In addition, care should be taken to make sure that finite element geometry is properly constrained (by appropriate boundary conditions) and there are no rigid body modes. Details on the guidelines for implementing nonlinear contact interactions in a finite element program can be found in literature [4, 21, 26-29].

In the current model, the contact between interacting surfaces is incorporated using "surface-tosurface" contact with "no separation but sliding permitted" option. The amount of sliding depends on the frictional model, which is defined according to Coulumb's frictional law with a constant co-efficient of friction of $\mu=0.3$ (assuming Class A faying surfaces) throughout the analysis[30].

To determine the optimum set of contact parameters, a sensitivity study was carried out by varying the contact stiffness from 0.01 to 1 (as suggested in the ANSYS contact technology guide) [22] . The upper bound value of contact stiffness is more appropriate for bulk deformation problems and the lower bound value is appropriate for bending deformation dominated problems (similar to the current one). Based on the results of the sensitivity study, an optimum normal contact stiffness $(\mathrm{FKN})$ value of 0.1 was assumed in the first iteration of the analysis. This value is updated in subsequent iterations based on the current mean stress of the underlying element and the allowable penetration of contact elements. 


\subsection{High-temperature material properties}

To accurately model the behavior of double angle connection, appropriate thermal and mechanical properties of constitutive materials should be specified as input in ANSYS. The thermal properties include density, thermal conductivity and specific heat while the mechanical properties include the stress-strain relationships of steel, all of which vary as a function of fire temperature. For the thermal properties, empirical relations of steel provided in Eurocode 3 [6] are used while the empirical relations of concrete specified in Eurocode 2 [31] for siliceous aggregate are used. The thermal conductivity, specific heat and dry density of fire insulation (spray applied fire resistive material i.e., SFRM) are assumed to be $0.086 \mathrm{~W} / \mathrm{m} . \mathrm{K}, 900 \mathrm{~J} / \mathrm{kg} \mathrm{K}$ and $240 \mathrm{~kg} / \mathrm{m}^{3}$, respectively. These are based on the values proposed for spray applied fire resistive material (SFRM) used in literature [32].

All the beams and angles used in the test assembly were made with ASTM A992 Grade 50 steel, while the bolts were $22 \mathrm{~mm}$ in diameter and made of ASTM A490 Grade steel. Both the connection assemblies were insulated with $12.7 \mathrm{~mm}$ spray-on fire resistive material (SFRM) applied on all three sides of the secondary beam along the majority of its length. An insulation thickness of $12.7 \mathrm{~mm}$ corresponds to a nominal fire resistance rating of 1-hour.

For assembly S2 a concrete deck was cast on steel frame to provide rigidity against lateral torsional buckling. The design compressive strength was $28 \mathrm{MPa}$ with an actual strength $41 \mathrm{MPa}$ on the day of testing of the slab. The batch proportions of concrete are shown in Table 2. A steel deck of $3454 \mathrm{~mm}$ by $3658 \mathrm{~mm}$ was attached to the secondary beams through shear studs spaced at $152 \mathrm{~mm}$ along the length of the secondary beam. The shear studs were of $19 \mathrm{~mm}$ diameter and $99 \mathrm{~mm}$ long and were spaced at $152.4 \mathrm{~mm}$ along the length of the secondary beam resulting in 67 $\%$ composite action. The concrete slab of $114 \mathrm{~mm}$ was cast on $6 \times 6-\mathrm{W} 1.4 \times \mathrm{W} 1.4$ welded wire fabric shrinkage reinforcement. The slab was cast with light weight concrete supplied from a local concrete batch mix plant.

The properties for steel members used in the current model are based on ambient temperature tensile coupon tests reported in Table 1. For the properties of bolts presented in Table 1, the ambient temperature yield strength and ultimate strength of bolts are based on ASTM A490 [33] specifications while the modulus of elasticity was assumed to be $210 \mathrm{GPa}$ and the ultimate strain is based on Eurocode 3 provisions. 
These mechanical properties along with the constitutive relations provided in Eurocode 3 [6] are used to generate nominal stress-strain-temperature relationships. The nominal stress-strain curves are converted into true stress-strain curves using the following relationship:

$$
\sigma_{\text {true }}=\sigma_{\text {nom }}\left(1+\varepsilon_{\text {nom }}\right) \text { and } \varepsilon_{\text {true }}=\ln \left(1+\varepsilon_{\text {nom }}\right)
$$

where $\sigma_{\text {true }}, \varepsilon_{\text {true }}$ represent true stress and strain while $\sigma_{\text {nom }}, \varepsilon_{\text {nom }}$ represent nominal stress and strain respectively. Nominal stress-strain curves are based on standard tensile test coupon in which the area and length of the specimen changes continuously. However, these dimensional changes are not accounted for in nominal stress-strain relationships. On the other hand, true stress-strain relationships account for the dimensional changes and hence they provide a realistic representation of the material behavior. Therefore, true stress-strain relationships are used in the current model.

The compressive strength of concrete used in the slab is taken as $41 \mathrm{MPa}$. The reduction factors specified in Eurocode 2 [31] are used to estimate the elevated temperature constitutive relations for concrete. Since the insulation material has significantly low strength and stiffness, the strength contribution from the insulation is neglected. However, thermal properties of SFRM insulation are accounted for in the thermal analysis. The thermal properties of insulation at elevated temperatures are assumed to be same as that at room temperature due to lack of data on the variation of insulation properties with temperature.

All the connection components (beam, column, double angle and bolts) are assumed to follow the elasto-plastic material behavior with Von-Mises plasticity yielding criterion and an isotropic hardening rule.

\subsection{Failure criteria and Numerical convergence}

The failure criteria adopted in the current model is the one based on limiting an equivalent plastic strain. Accordingly, the "failure" is defined as the time when the maximum equivalent plastic strain within a time step exceeds $15 \%$. When the strain level reaches this limiting value, the governing finite element equations do not converge to an equilibrium solution.

Numerically, convergence in the structural model is governed by the Newton-Raphson equilibrium iterations [24]. In the structural model simulations, force convergence is said to be achieved if the error between successive iterations is less than $0.5 \%$ (i.e., having an accuracy of $99.5 \%$ ) [34]. Similarly, in thermal analysis the temperature convergence is assumed to be 
reached when the temperature difference at each node between successive equilibrium iterations is less than $0.5^{\circ} \mathrm{C}$.

\subsection{Model validation}

The ANSYS finite element model is validated by comparing response predictions from the analysis with measured data in fire experiments [23]. During fire tests, gravity load was applied on the beams prior to heating the sub frame assembly. Loading on the assemblies comprised of four point loads, applied at two points along each secondary beam, as shown in Fig. 6(a)-(b). The point loads on the secondary beams were separated by a distance of $864 \mathrm{~mm}$. The magnitude of load at each actuator loading point was $74.7 \mathrm{kN}$ in assembly $\mathrm{S} 1$ and $92.2 \mathrm{kN}$ in assembly S2, which correspond to a load ratio (level) of $40 \%$ and $50 \%$ of the secondary beam ultimate moment capacity. The load ratio (LR) is defined as the ratio of applied bending moment in the beam under fire conditions to the ambient temperature plastic bending moment capacity of the beam. The rationale for choosing a higher load ratio for assembly S2 is to take in to account the beneficial effect of the concrete slab that enhances capacity of the secondary beam. To circumvent the problem of high-stress concentrations and numerical singularities due to external loading, the base of actuator pads was modeled and the load is applied as nodal force in vertical direction (y direction). The loading was applied 30 minutes prior to the start of the test to ensure that the deflections reached a steady state before the start of the fire.

After 30 minutes of load application, assembly S1 was exposed to design fire, DF1, which comprised of a growth phase for the first 75 minutes as per ASTM E119 fire [35] and then a decay phase with a cooling rate of $8{ }^{\circ} \mathrm{C} / \mathrm{min}$. Similarly, S2 was exposed to design fire DF2, which had a growth phase as per ASTM E119 standard fire for the first 90 minutes and then followed by a decay phase with a cooling rate of $15{ }^{\circ} \mathrm{C} / \mathrm{min}$. Different decay rates were used in S1 and S2 to quantify the effect of cooling rate on the fire response of connection assemblies. Similarly, different durations of fire growth phase were used to take advantage of the heat sink effect provided by the concrete slab. The predicted and the measured time-temperature relationship of DF1, DF2 are illustrated in Fig. 7.

Fig. 8 shows the comparison between measured steel temperature and that predicted by finite element model in the connection assemblies S1 and S2. It can be seen that there is a good agreement between predicted and measured temperatures at various points in the steel section of 
secondary beams. In both the assemblies, temperatures at the bottom flange were higher than that of the top flange and this can be attributed to the closer vicinity of bottom flange to fire. In addition bottom flange is exposed to fire on top and bottom surfaces as opposed to bottom surface of top flange only. However, the maximum average temperatures reached in sub frame S2 were lower as compared to that of sub frame S1, and this can be attributed to the heat sink effect provided by the concrete slab to the top flange of the beams.

Figs. 8(a) and 8(b) show that the predicted temperatures in both connection assemblies were initially conservative because the computational thermal model does not account for the evaporation of the insulation's residual water near $100{ }^{\circ} \mathrm{C}$, which slowed the initial increase of temperature. The discrepancy in the temperatures during the cooling phase can be attributed to the movement (dislocation) of thermocouple when the top flange experienced local buckling. Temperature variation between the computational and experimental results may also have been caused by variation in the actual insulation thickness as compared to the idealized constant 12.7$\mathrm{mm}$ thickness used for computational thermal analysis. Therefore, it can be concluded that the thermal sub model in ANSYS is capable of predicting steel temperatures with good accuracy. A comparison of predicted and measured connection rotation is plotted as a function of fire exposure time in Fig. 9. The values of rotation are evaluated using vertical deflection of the secondary beams (measured by the LVDT's at the loading points) and the distance from the connection to the loading point. It can be seen from the figure that the predicted rotations from the model closely follow those measured during fire test. In both the assemblies, rotation gradually increases with time during the early stages of fire, and this is mainly due to deteriorating strength and modulus properties of steel as well as increasing expansion of steel with temperature. However, during the fire test, assembly S1 experienced a sudden increase in rotation at 65 minutes into the fire test. This is due to onset of local and lateral torsional buckling in the secondary beam which led to the failure of sub frame assembly S1 in 65 minutes. The current model captures sudden increase in connection rotation and predicts a failure time of around 60 minutes for $\mathrm{S} 1$, which is close to 65 minutes failure time measured during the test. The deformed shape predicted by the model, shown in Fig. 10, indicates that the secondary beam experienced local and lateral torsional buckling similar to that observed during the test. The 
deformed shape of the secondary beam in assembly S1 observed during the test is shown in Fig. 11 for comparison purpose.

The rotation response of connections in sub frame S2 progressed similar to that in sub frame S1, but the connection experienced higher rotation without any instabilities. This can be attributed to the higher rigidity provided by the slab which enhanced the overall capacity of the beams and in turn the connections. The rate of rotation in connections decreased steadily after reaching a peak value. This is on expected lines because as soon as the cooling phase of fire started, beams regained some of their initial strength and stiffness and thus the rotations started to decrease. A comparison of predicted and measured vertical deflections (at loading point) in the secondary beam for assemblies S1 and S2 are plotted in Fig. 12. It can be seen from the figure that the vertical deflection of assembly S1 increases during early stages of fire (0-60 minutes). This is due to gradual deterioration of strength and stiffness properties of steel with increasing temperature. However, the model predicts a sudden increase in vertical deflection around 60 minutes. This sudden increase is due to the fact that secondary beam experienced failure by local and lateral torsional buckling (as shown in Fig. 10). The predicted failure time of around 60 minutes for $\mathrm{S} 1$, is comparable to 65 minutes failure time measured during the test. As the assembly S1 failed at 60 minutes, the response of assembly beyond 60 minutes cannot be simulated by the model.

Similar to S1, the vertical deflection of secondary beam in assembly S2 increases with time during the initial stage (0-90 minutes) of fire. The increase in deflection can be attributed to gradual deterioration of strength and stiffness properties of steel with increasing temperature. The vertical deflection of secondary beam starts to decrease (beyond 90 minutes) after reaching a maximum value. This is on expected lines because as soon as the cooling phase of fire starts, the secondary beam regains some of its initial strength and stiffness and thus the vertical deflection in secondary beam starts to decrease.

Therefore, based on the assumptions considered in modeling the connection assembly and response i.e., deformed shape predicted from the ANSYS analyses, it can be concluded that the above developed finite element model is capable of simulating fire behavior of connection assemblies with a good accuracy. 
It should be noted that the predicted temperature-time history of assemblies S1 and S2 are based on the assumption that thermal properties of insulation (SFRM) remain invariant at elevated temperatures. This is due to lack of reliable data on the effect of temperature on the thermal properties of SFRM. However, recent research [36] showed that there is variability in the thermal properties of different types of SFRM even at room temperature, apart from the temperature-dependency of thermal properties of fire insulation in general. Hence, use of temperature dependent thermal properties of SFRM in numerical model(s) can provide more realistic fire response of structural assemblies. However, currently there are knowledge gaps in this arena and further research is needed not only to establish reliable temperature dependent thermal property data of SFRM, but also to evaluate the effect of such variation on the fire response of structural members.

\section{PARAMETRIC STUDIES}

The finite element model validated in Section 2 is applied to study the effect of fire decay rate, loading type, presence of the slab and degree of axial restraint on the fire performance of double angle connection assemblies. The analysis in all cases, except for the case of fire decay rate, was carried out by subjecting the connection assemblies S1, S2 to design fires DF1 and DF2, respectively. To study the effect of decay rate, assembly S1 was subjected to modified design fire DF1 (as shown in Fig. 13(a)) which had a growth phase of 45 minutes instead of 75 minutes. Similarly, connection assembly S2 was subjected to modified design fire DF2 (as shown in Fig. 13(b)) which had a growth phase of 120 minutes instead of 90 minutes. Detailed description of the results obtained from parametric studies is presented below.

\subsection{Cooling (Decay) rate}

It is well known that the presence of decay phase in a fire significantly influences the connection behavior. This is due to the fact that cooling phase of fire directly dictates the rate of strength, stiffness and thermal shrinkage recovery in the connected beam which in turn influence the development of tensile forces in connection region. To study this effect of cooling phase of fire, connection assemblies were analyzed by varying the decay rate of both design fires from $25 \%$ to $150 \%$ of the initial decay rates $\left(8^{\circ} \mathrm{C} / \mathrm{min}\right.$ for DF1 and $15^{\circ} \mathrm{C} / \mathrm{min}$ for DF2) i.e., the decay rate of design fire DF1 was varied from $2{ }^{\circ} \mathrm{C} / \mathrm{min}$ to $12{ }^{\circ} \mathrm{C} / \mathrm{min}$ while that of DF2 was varied from 3.75 ${ }^{\circ} \mathrm{C} / \mathrm{min}$ to $22.5{ }^{\circ} \mathrm{C} / \mathrm{min}$. In a real building fire scenario, once the compartment enters cooling phase the rate of cooling is dictated by the availability of fuel and oxygen supply and also 
properties of lining materials. In some cases, the high temperature of fire might damage the windows allowing huge supply of oxygen whereas in other cases the amount of fuel might run out leading to low supply of oxygen. Therefore, the cooling rates considered in this study are representative of the typical scenarios encountered in a real building fire.

Fig. 14 shows the predicted rotation in connections of both assemblies for varying decay rate scenarios. For assembly S1, it can be seen from the figure that with varying decay rate the connection response remains similar in initial stage. In all cases (except for $10{ }^{\circ} \mathrm{C} / \mathrm{min}$ ) sub frame experienced failure due to onset of instability in the beam (local and lateral torsional buckling) immediately after the start of decay phase. Therefore, no specific conclusions can be drawn for assembly S1.

During the initial stages of fire, rotation in connection of assembly S2 progressed similar to that of S1 for all decay rates considered. On the other hand, connections in assembly S2 experienced much higher rotations (without any instabilities) in comparison to assembly S1. This can be attributed to higher rigidity provided by the slab which enhanced the overall strength of the beams. However, the failure time of the assembly decreased with increase in decay rate. This can be attributed to the fact that at higher decay rates, the beam experiences large changes in temperature (thermal gradient) which in turn leads to the development of higher thermal shrinkage forces in connection. Therefore, the connection is not able to sustain external loading for a longer duration as compared to the cases of lower decay rates.

Based on these observations, it can be concluded that lower rate of decay in a design fire scenario improves the fire performance of the connection by decreasing the magnitude of thermal shrinkage forces developed in connections.

\subsection{Loading type}

The type of loading on the beam can significantly influence the response of connection, especially under fire conditions, due to its effect on the moment generated in the beam. The magnitude and shape of moment diagram governs the resulting deflection in connected members (beam), rotations in connection, contact forces between bolt shanks and bolt holes, stress concentrations in the beam and in the connection region. The effect of loading type on the fire response of connections can be illustrated by reviewing the results presented in Fig. 15. During the fire test, the frame assemblies were subjected to two point loads (as shown in Fig. 6(b)) on 
each secondary beam. In the analysis, the assemblies were analyzed by applying two loading scenarios namely, four point loads and uniformly distributed load along each secondary beam. A schematic of loading scenarios is illustrated in Fig. 16. The magnitude of four point and distributed loading is selected such that it produced the same maximum moment in the secondary beam as compared to the case of two-point loading. The magnitude of each loading point for the case of four point loading was $46.3 \mathrm{kN}, 57.8 \mathrm{kN}$ while that for uniformly distributed loading was $63.5 \mathrm{kN} / \mathrm{m}, 79.3 \mathrm{kN} / \mathrm{m}$ for connection assemblies S1 and S2, respectively.

It can be seen from Fig. 15(a) that the connections, in assembly S1, with two point and four point loading experienced gradual increase in rotation during the early stages of fire till they experienced failure (by sudden increase in rotation) around 60 minutes into fire. This increase in rotations is due to deteriorating strength and stiffness properties of steel as well as increased thermal expansion of steel with temperature. However, when the sub frame assembly was analyzed with distributed loading, it experienced failure with a sudden increase in rotation at the start of the analysis itself. A review of the deformed shape of the frame assembly S1, shown in Fig. 17(b), indicated that the secondary beam rotated and experienced lateral torsional buckling which led to the failure of the assembly. This is on the expected lines since the secondary beam was not continuously braced (against lateral movements) and the distributed loading created instability in the form of lateral torsional buckling.

Compared to assembly S1, rotations in connection in assembly S2 (Fig. 15(b)) increased with time during the early stages (growth phase) of fire followed by a decrease during the later stages. The increase in rotation during early stages is due to decreasing moment capacity and stiffness of the beam while the decrease during later stages can be attributed to the fact that beam regained part of its initial strength during the decay phase of fire. It can also be seen from the figure that the connections in the frame analyzed with distributed loading scenario were able to sustain higher rotation (almost $50 \%$ more) compared to two and four-point loading scenarios. This can be attributed to the fact that the distributed loading produced a parabolic increase in moment compared to linear variation in moment generated in two and four point loading cases. The parabolic moment distribution leads to the development of higher stresses and deflection in the beam which results in higher rotation in connections. 
Based on the rotation response in connections, it can be inferred that (a) distributed loading represents the extreme loading case scenario for both connection assemblies, (b) for laterally unsupported connection assemblies (i.e., without the slab), distributed loading creates instability in the beam leading to failure of the assembly, and (c) presence of the slab stabilizes and enhances the load carrying capacity of connection assembly while sustaining higher rotations generated by applied distributed loading.

\subsection{Effect of axial restraint}

In a typical steel frame building, double angle connections are integral part of structural frame and their fire performance will be highly influenced by the restraint offered by the adjacent structural members. To study this effect, sub frame assemblies S1 and S2 were analyzed by subjecting to four different values of axial restraint stiffness such as $25 \%, 50 \%, 75 \%$ and 100 $\%$ of the secondary beam stiffness. The axial restraint considered in this study is the one generated by the flexural rigidity of the secondary beam and is assumed to be arising from the

presence of secondary beam in the adjacent sub frame. The value of axial restraint (stiffness) of the beam was computed by:

$$
k=\frac{E A}{L}
$$

where $k$ is the value of axial restraint, $E, A$ and $L$ are the room-temperature elastic modulus of steel, cross-sectional area and length of the secondary beam, respectively.

In the finite element model, the presence of axial restraint is simulated by using a spar element (LINK180), available in ANSYS. Nodes at one end of the spar elements were connected to the perimeter beam while the nodes at the other end were completely fixed in all three directions (x,y and $\mathrm{z}$ ), as shown in Fig. 18.

Fig. 19 shows the progression of rotation in connection as a function of fire exposure time for different values of axial restraint stiffness. It can be seen from Fig. 19(a) that the presence of axial restraint significantly affects the fire response of sub frame S1 and the failure time decreases with increasing axial stiffness. This can be attributed to the fact that higher axial stiffness (restraint) limits the amount of free thermal expansion that secondary beam can undergo [37] [38]. This restrained movement of the beam results in the development of higher stresses 
and local instabilities in the beam which ultimately leads to the failure of the connection assembly. Failure modes of assembly S1 for different values of axial restraint stiffness, obtained from the analysis, are shown in Fig. 20. As can be seen from the figure, increasing axial restraint from $25 \%$ to $100 \%$ increased the instability of beam from local buckling of web to crippling of web and flanges in the beam. Sub frame assembly S2 survived the entire duration of fire exposure without any instabilities (as shown in Fig. 19(b)).

A comparison of rotation in connections, in Fig. 19(b), indicates that the axial restraint stiffness has marginal influence on the fire response of assembly S2. This is on expected lines since sub frame assembly $\mathrm{S} 2$ had concrete slab which led to increase in the rigidity and thus enhanced the overall strength of the secondary beams and in turn the strength of connections. Further, in assembly S2 presence of the slab stabilized secondary beam and prevented any local instabilities as compared to that in sub frame assembly $\mathrm{S} 1$.

Based on the rotation response in connection and the deformed shape, it can be concluded that

higher value of axial restraint stiffness decreases the failure time of sub frame assembly S1 by restricting free thermal movement of the beam. On the other hand, axial restraint stiffness has negligible influence on sub frame assembly S2 because of the presence of the concrete slab.

\section{CONCLUSIONS}

Based on the results presented in the paper, the following conclusion can be drawn:

- The proposed 3-D finite element models are capable of simulating thermal and structural response of sub frame assemblies with double angle connections and accounts for material, geometric nonlinearities and non-linear contact interactions.

- Presence of the concrete slab restrains the secondary beam against lateral torsional buckling and significantly enhances the rigidity of connection under fire conditions.

- In beam-slab assemblies, a slower rate of decay of fire enhances fire performance by decreasing the amount of thermal shrinkage forces in connections.

- Uniformly distributed loading scenario represents the extreme loading case scenario for connection assemblies as compared to that of point loading scenario. For laterally unrestrained assemblies (i.e., without the slab), distributed loading creates beam 
instabilities in the form of lateral torsional buckling leading to premature failure of the assembly.

- Axial restraint stiffness significantly influences the fire response of connection assemblies without the slab. The failure time decreases with increasing axial stiffness because a higher value of axial restraint stiffness restricts the free thermal movement of the beam. This results in the development of higher stresses and local instabilities in the beam which ultimately leads to the failure of the connection assembly.

\section{RESEARCH IMPLICATIONS}

The research presented in this paper provides an insight into the transient behavior of full-scale connection assemblies. Though the connections were subjected to heating in an indirect way, the connections had an influence on the behavior of connected beams and hence on the entire assembly. This is due to the fact that the fire behavior of full-scale connection assemblies is highly interdependent on the behavior of end connections, as well as the connected structural members.

Currently, there is lack of data to characterize the transient behavior of full-scale connection assemblies (with partially or fully heated connections). In addition, as detailed in Section 2.6, further research is needed to establish reliable temperature dependent thermal property data of SFRM and also to evaluate the effect of such variation on the fire response of structural members. The results presented in this paper are a first step towards understanding the differences in the fire behavior of assemblies from a system-level. Further studies to provide an insight into the transient fire performance of full-scale connection assemblies with fully heated connections are currently underway at Michigan State University.

\section{ACKNOWLEDGEMENTS}

This material is based upon work supported by the National Science Foundation (NSF) under Grant No. CMMI-0757900 to Michigan State University. Any opinions, findings, and conclusions or recommendations expressed in this paper are those of the authors and do not necessarily reflect the views of the sponsors.

\section{REFERENCES}


[1] Al-Jabri KS, Lennon T, Burgess IW, Plank RJ. Behaviour of steel and composite beamcolumn connections in fire. Journal of Constructional Steel Research. 1998;46:308-9.

[2] Al-Jabri KS, Seibi A, Karrech A. Modelling of unstiffened flush end-plate bolted connections in fire. Journal of Constructional Steel Research. 2006;62:151-9.

[3] Wang YC, Kodur VKR. Research toward use of unprotected steel structures. Journal of Structural Engineering-Asce. 2000;126:1442-50.

[4] Pakala P, Kodur V, Dwaikat M. Critical factors influencing the fire performance of bolted double angle connections. Engineering Structures. 2012;42:106-14.

[5] Yu H, Burgess IW, Davison JB, Plank RJ. Tying capacity of web cleat connections in fire, Part 1: Test and finite element simulation. Engineering Structures. 2009;31:651-63.

[6] Eurocode3. Design of steel structures, Part 1.2: General rules-structural fire design, Document CEN, European Committee for Standardization, UK. 2005.

[7] Al-Jabri KS, Davison JB, Burgess IW. Performance of beam-to-column joints in fire - A review. Fire Safety Journal. 2008;43:50-62.

[8] Bailey CG, Burgess IW, Plank RJ. Analyses of the effects of cooling and fire spread on steelframed buildings. Fire Safety Journal. 1996;26:273-93.

[9] Liu TCH, Fahad MK, Davies JM. Experimental investigation of behaviour of axially restrained steel beams in fire. Journal of Constructional Steel Research. 2002;58:1211-30.

[10] Liu TCH. Finite element modelling of behaviours of steel beams and connections in fire. Journal of Constructional Steel Research. 1996;36:181-99.

[11] El-Houssieny OM, Salam SA, Attia GAM, Saad AM. Behavior of extended end plate connections at high temperature. Journal of Constructional Steel Research. 1998;46:299-.

[12] Daryan AS, Yahyai M. Modeling of bolted angle connections in fire. Fire Safety Journal. 2009;44:976-88.

[13] Azizinamini. Monotonic response of semi-rigid steel beam to column connections. Columbia: University of South Carolina; 1982.

[14] Daryan AS. A study on behavior of connections in fire. Tehran, Iran: K.N. Toosi University; 2006.

[15] Saedi Daryan A, Yahyai M. Behavior of bolted top-seat angle connections in fire. Journal of Constructional Steel Research. 2009;65:531-41.

[16] Mao CJ, Chiou YJ, Hsiao PA, Ho MC. Fire response of steel semi-rigid beam-column moment connections. Journal of Constructional Steel Research. 2009;65:1290-303. 
[17] Garlock ME, Selamet S. Modeling and Behavior of Steel Plate Connections Subject to Various Fire Scenarios. Journal of Structural Engineering-Asce. 2010;136:897-906.

[18] Selamet S, Garlock ME. Robust fire design of single plate shear connections. Engineering Structures. 2010;32:2367-78.

[19] Selamet S, Garlock MEM. Local buckling study of flanges and webs in I-shapes at elevated temperatures. ASCE structures congress. Orlando, FL2010. p. 1592-603.

[20] Pakala P, Kodur V. System-level approach to predict the transient fire response of double angle connections. Journal of Constructional Steel Research. 2013;89:132-44.

[21] Selamet S, Garlock M. Guidelines for modeling three dimensional structural connection models using finite element methods. International Symposium "Steel Structures: Culture \& Sustainability". Istanbul, Turkey2010.

[22] ANSYS Inc. ANSYS Contact Technology Guide2009.

[23] Pakala P, Kodur V, Selamet S, Garlock M. Fire behavior of shear angle connections in a restrained steel frame. Journal of Constructional Steel Research. 2012;77:119-30.

[24] ANSYS Inc. ANSYS element reference2009.

[25] Eurocode1. Actions on structures, Part 1-2: General actions-Actions on structures exposed to fire, Document CEN, European Committee for Standardization, UK. 2002.

[26] Bursi OS, Jaspart JP. Benchmarks for finite element modelling of bolted steel connections. Journal of Constructional Steel Research. 1997;43:17-42.

[27] Bursi OS, Jaspart JP. Calibration of a finite element model for isolated bolted end-plate steel connections. Journal of Constructional Steel Research. 1997;44:225-62.

[28] Bursi OS, Jaspart JP. Basic issues in the finite element simulation of extended end plate connections. Computers \& Structures. 1998;69:361-82.

[29] Van der Vegte GJ, Makino Y. Numerical Simulation of Bolted Connections: The Implicit versus the Explicit Approach. AISC-ECCS. Amsterdam, Netherlands2004.

[30] AISC. Manual of Steel Construction, Load and resistance factor design, 14th Edition, American Institute of Steel Construction Inc., Chicago. 2011.

[31] Eurocode2. Design of concrete structures, Part1-2: General rules-structural fire deisgn, ENV 1992-1-2, Document CEN, European Committee for Standardization, UK. 2004.

[32] Kodur VKR, Shakya AM. Effect of temperature on thermal properties of spray applied fire resistive materials. Fire Safety Journal. 2013;61:314-23. 
[33] ASTM. Designation A490 - 12 - Standard Specification for High-Strength Steel Bolts. West Conshohocken, PA2012.

[34] ANSYS Inc. ANSYS Command Reference2009.

[35] ASTM. Designation E119 - 11a - Standard Test Methods for Fire Tests of Building Construction and Materials. West Conshohocken, PA2011.

[36] Kodur V, Shakya A. Effect of temperature on thermal properties of spray applied fire resistive materials. Fire Safety Journal. 2013;61:314-23.

[37] Dwaikat MMS, Kodur VKR. A performance based methodology for fire design of restrained steel beams. Journal of Constructional Steel Research. 2011;67:510-24.

[38] Dwaikat M, Kodur V. Engineering approach for predicting fire response of restrained steel beams. Journal of Engineering Mechanics. 2010;137:447-61. 


\section{LIST OF TABLES}

Table 1: Summary of key mechanical properties of steel members used in the test assemblies

Table 2: Mix-proportions of the concrete used in the slab of test assembly S2

\section{LIST OF FIGURES}

Figure 1: Layout of the steel beams used in test assembly (plan view) [Location of double angle connections are highlighted in boxes]

Figure 2: Connection details used in test assembly (all dimensions in $\mathrm{mm}$ )

Figure 3: Test set-up of connection assembly S1

Figure 4: Test set-up of connection assembly S2 (a) prior to concrete casting (b) after concrete casting and (c) prior to fire test

Figure 5: Discretized geometry (quarter) of the connection assembly modeled in ANSYS

Figure 6: Layout of instrumentation and loading configuration used in the sub-frame assemblies

Figure 7: Predicted and measured time-temperature curves of design fires DF1 and DF2

Figure 8: Comparison of measured and predicted temperatures in tested assemblies (a) S1 and (b) S2

Figure 9: Comparison of predicted and measured connection rotation as a function of fire exposure time in test assemblies (a) S1 and (b) S2

Figure 10: Illustration of (a) deformed shape (b) local buckling of secondary beam and (c) lateral torsional buckling of secondary beam in assembly S1 as predicted by the numerical model

Figure 11: Illustration of (a) Local and (b) lateral torsional buckling experienced by the secondary beam in assembly $\mathrm{S} 1$ observed during the fire test

Figure 12: Vertical deflection of secondary beams (at loading actuator) predicted as a function of fire exposure time in test assemblies (a) S1 and (b) S2

Figure 13: Time-temperature curves for design fire scenarios used in the parametric study

Figure 14: Variation in connection rotation as a function of fire exposure time for different decay rates in assembly (a) S1 and (b) S2

Figure 15: Progression of connection rotation as a function of fire exposure time for sub frame assemblies (a) S1 and (b) S2 with different loading types

Figure 16: Illustration of different loading scenarios used in the analysis

Figure 17: Illustration of (a) deformed shape and (c) lateral torsional buckling of secondary beam in assembly $\mathrm{S} 1$ analyzed with uniformly distributed loading

Figure 18: Schematic of the spar elements used in the analysis

Figure 19: Effect of restraining axial stiffness on the fire response of double angle connection assemblies (a) S1 and (b) S2

Figure 20: Failure modes of connection assembly S1 for different values of axial restraint stiffness 


\section{TABLES}

Table 1: Summary of key mechanical properties of steel members used in the test assemblies

\begin{tabular}{|c|c|c|c|}
\hline Component & Beam & Angle & Bolts \\
\hline Elastic modulus $(\mathrm{MPa})$ & 187500 & 154000 & 210000 \\
\hline Yield strength (MPa) & 375 & 308 & 940 \\
\hline Maximum strength (MPa) & 451 & 459 & 1210 \\
\hline Ultimate strain (\%) & 16 & 23 & 20 \\
\hline
\end{tabular}

Table 2: Mix-proportions of the concrete used in the slab of test assembly S2

\begin{tabular}{|c|c|}
\hline Item & Quantity \\
\hline Type I Portland cement & $332 \mathrm{~kg} / \mathrm{m}^{3}$ \\
\hline Fly ash & $60 \mathrm{~kg} / \mathrm{m}^{3}$ \\
\hline Fine aggregate (sand) & $753 \mathrm{~kg} / \mathrm{m}^{3}$ \\
\hline Lightweight aggregate & $495 \mathrm{~kg} / \mathrm{m}^{3}$ \\
\hline Coarse aggregate (gravel) & $89 \mathrm{~kg} / \mathrm{m}^{3}$ \\
\hline Water & $161 \mathrm{~kg} / \mathrm{m}^{3}$ \\
\hline 28 day compressive strength & $34 \mathrm{MPa}$ \\
\hline
\end{tabular}


Figure 1

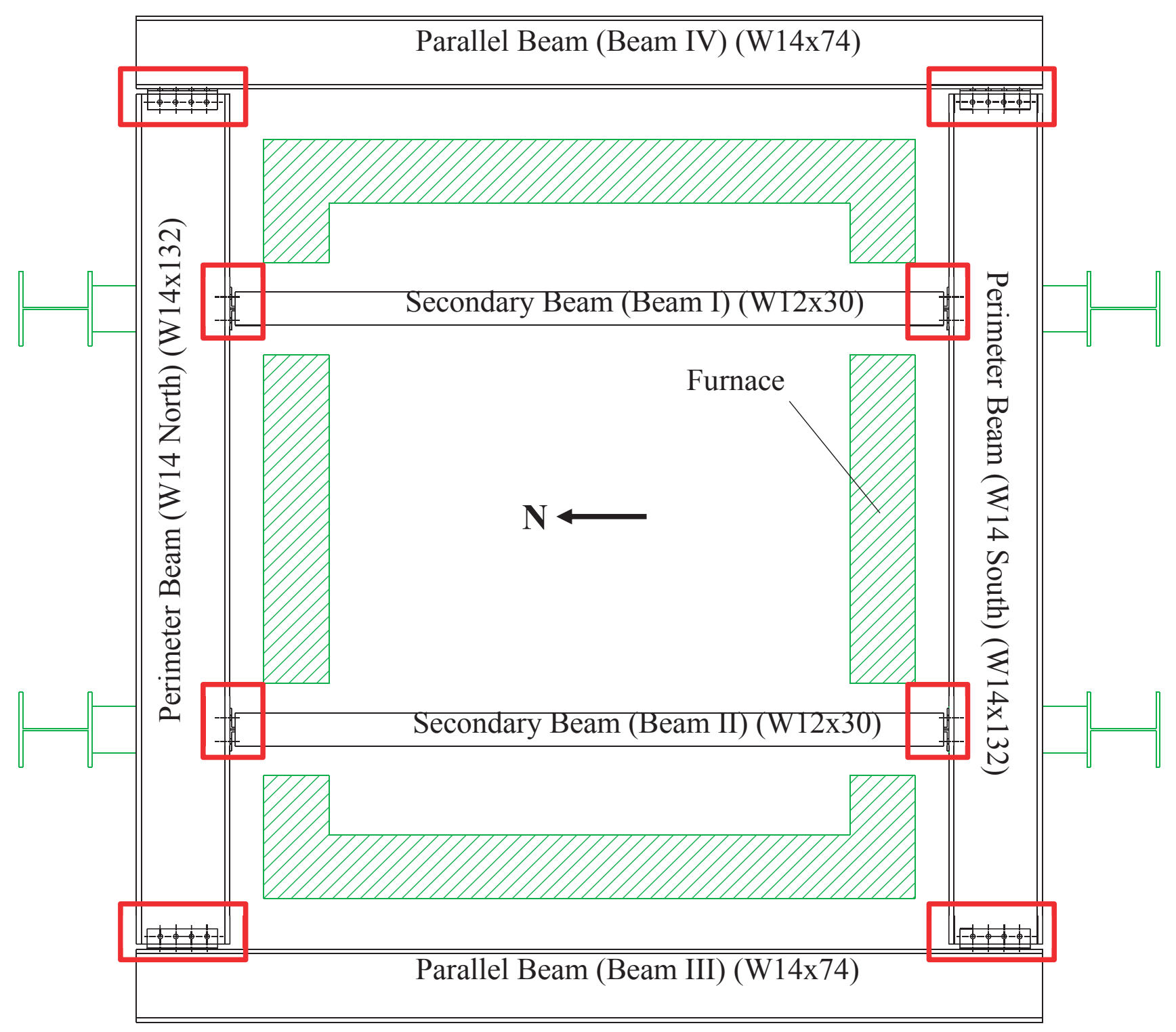


Figure 2

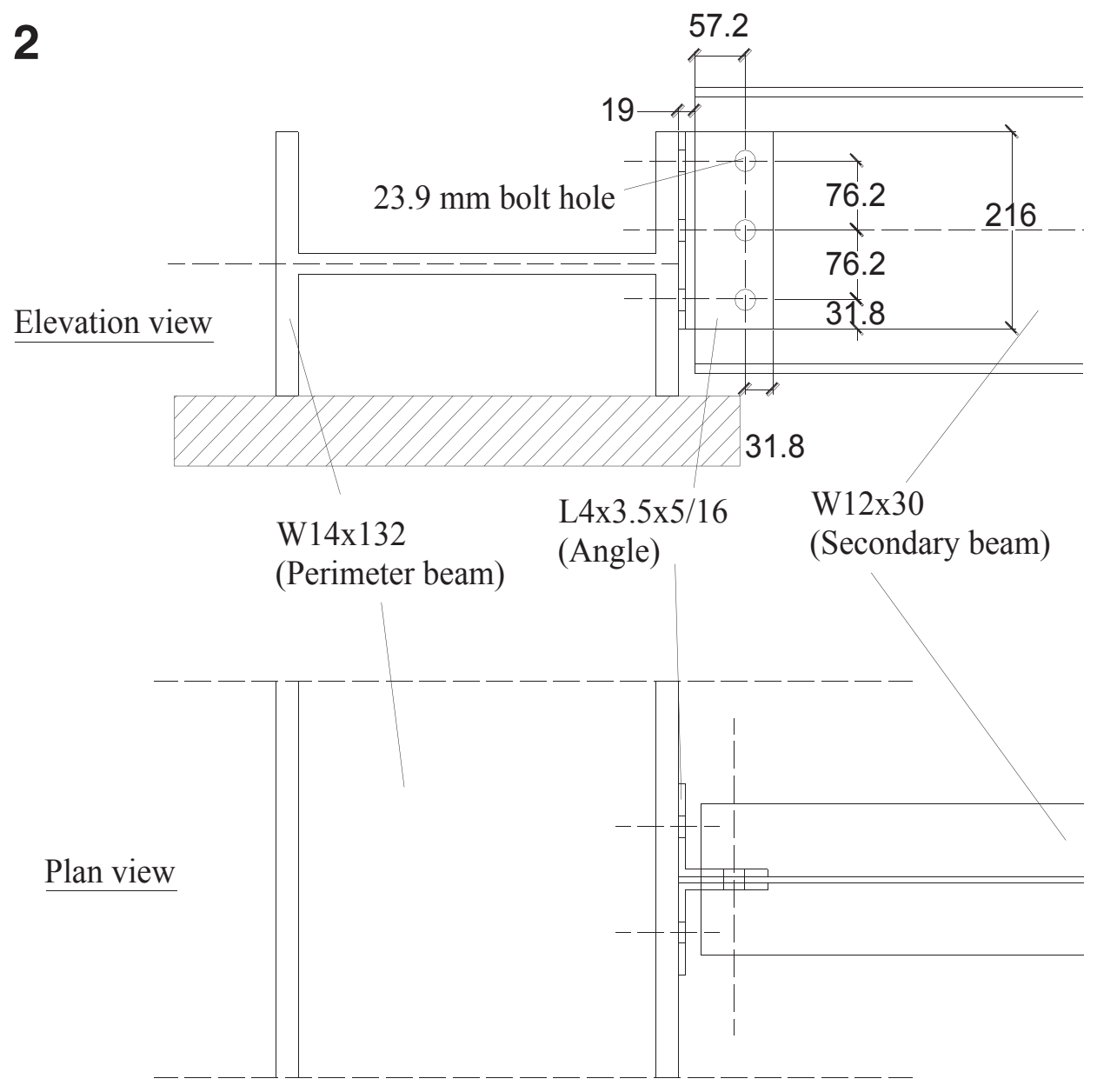

(a) Secondary and perimeter beam connection

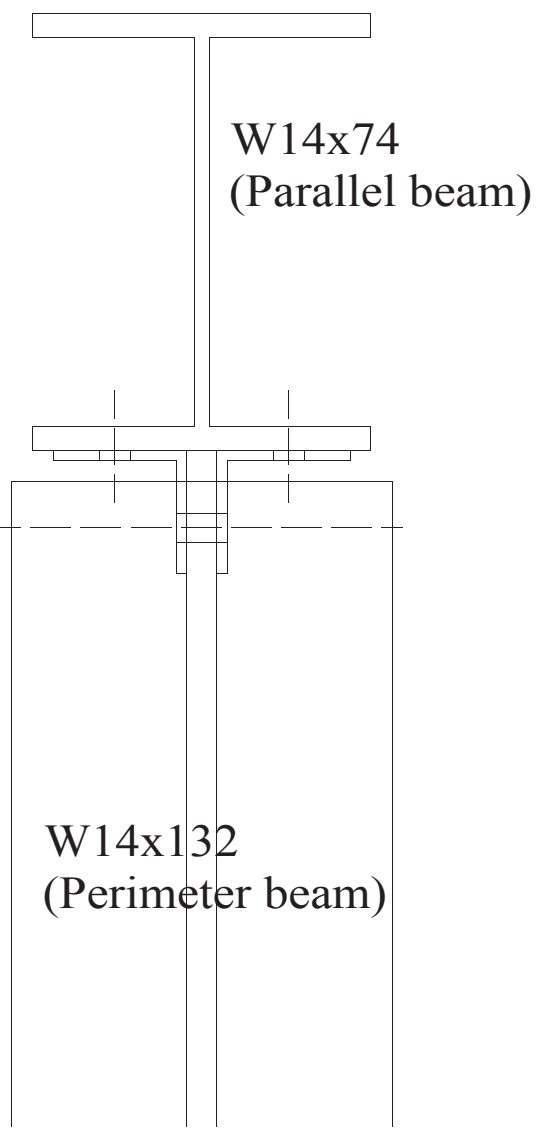

Plan view

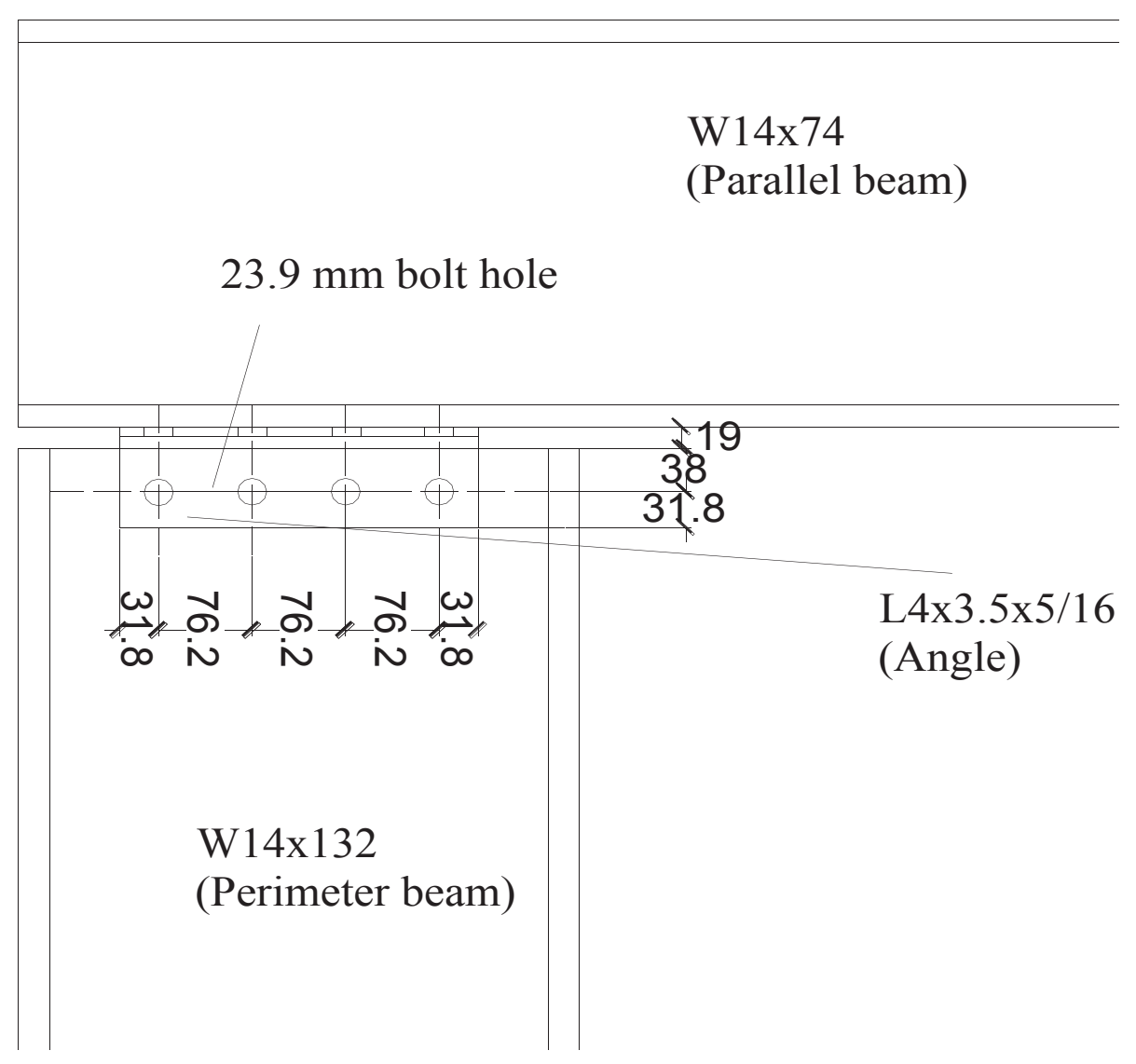

Elevation view

(b) Perimeter and parallel beam connection 
Figure 3

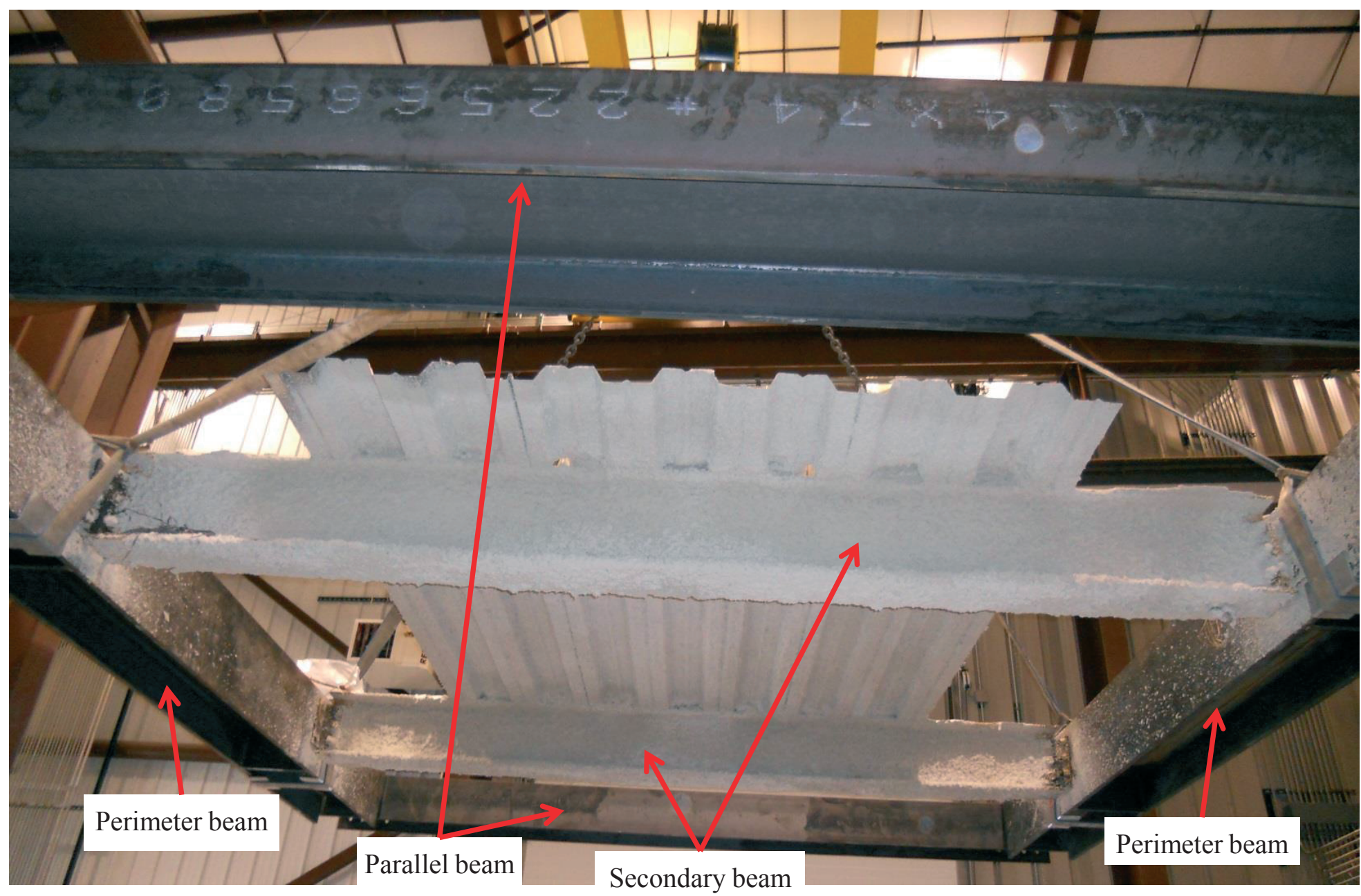




\section{Figure 4}

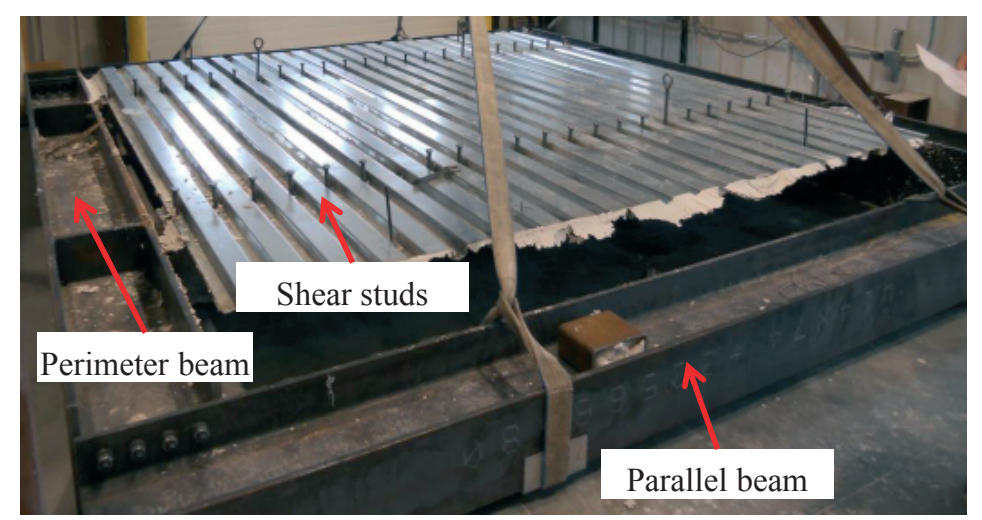

(a) Prior to concrete casting

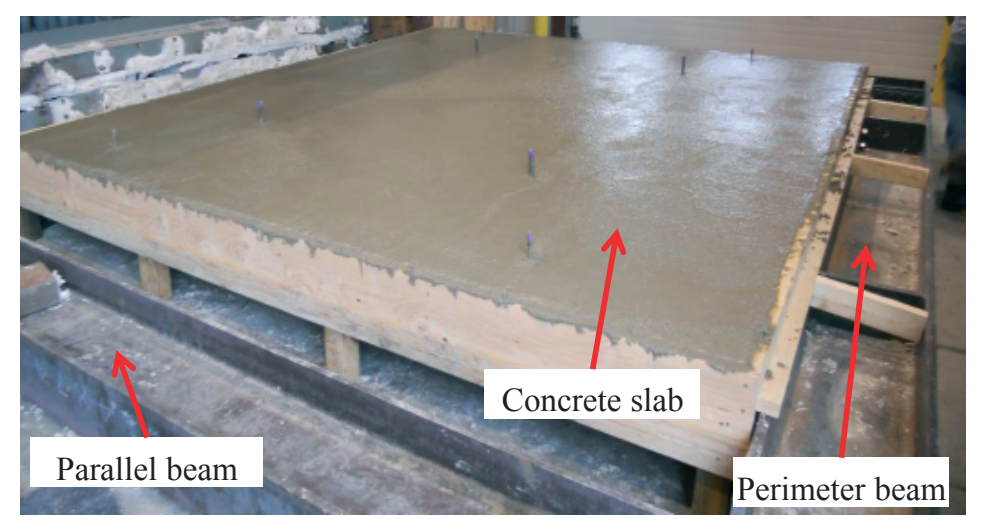

(b) After concrete casting

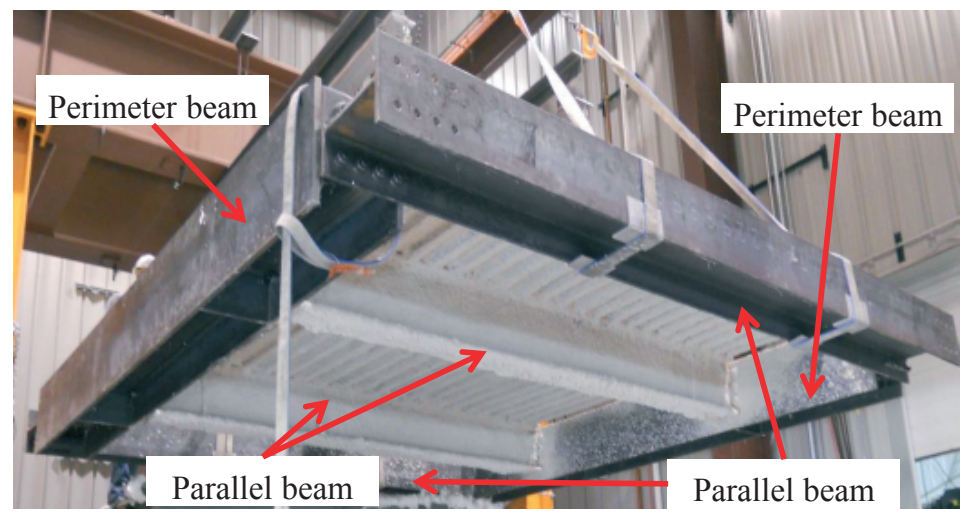

(c) Final assembly prior to fire test 


\section{Figure 5}

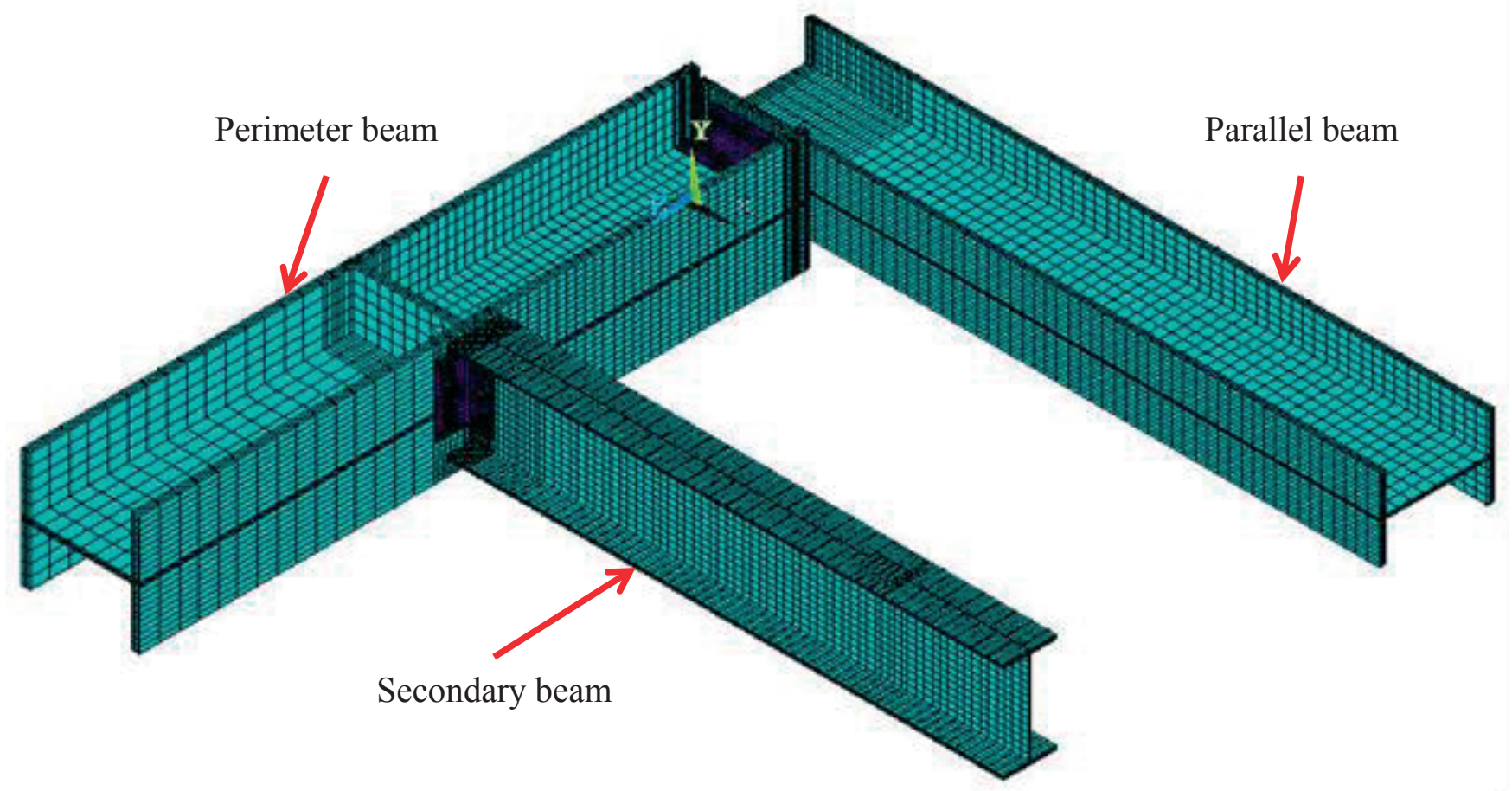

(a) S1

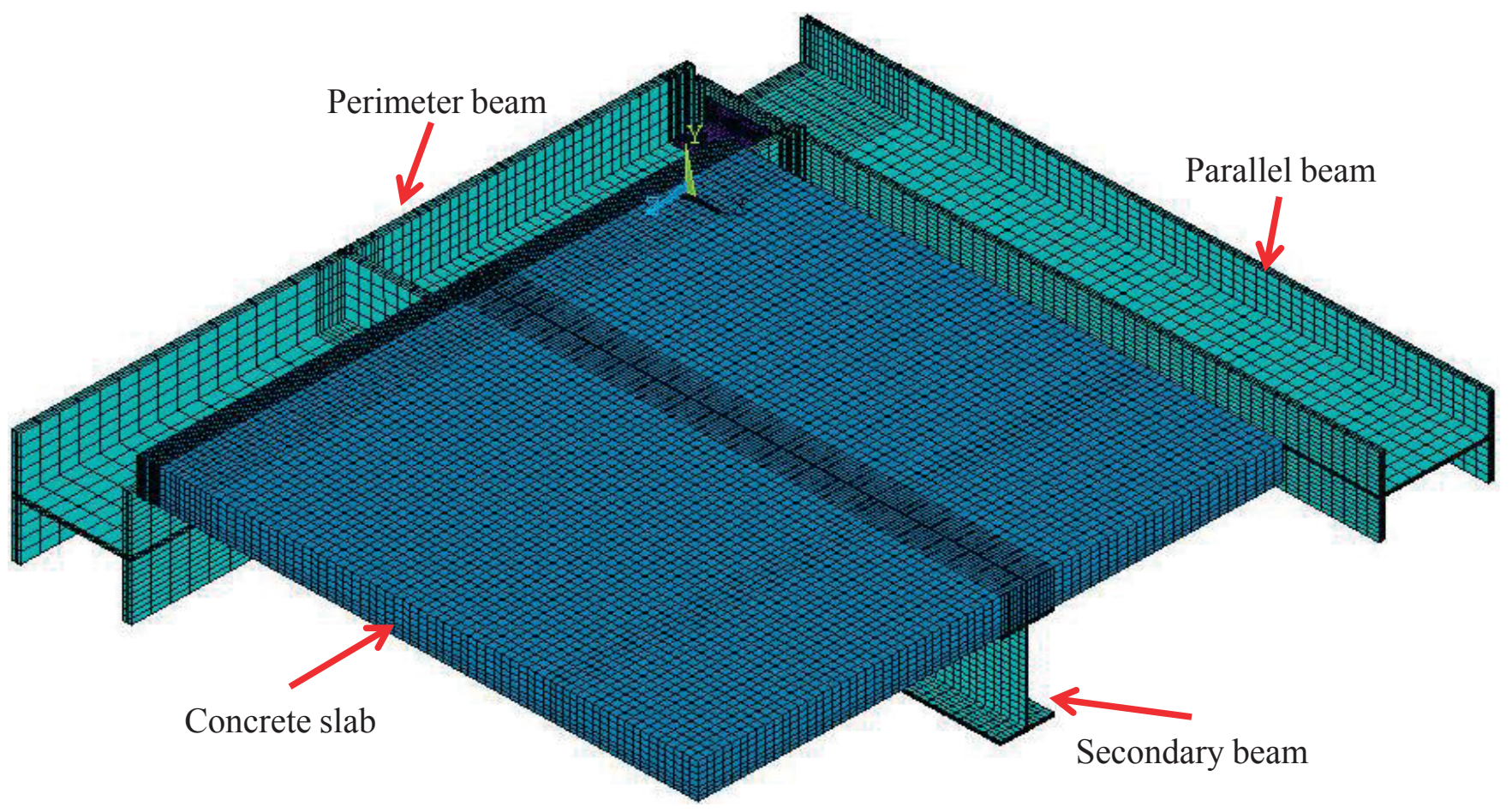

(b) S2 


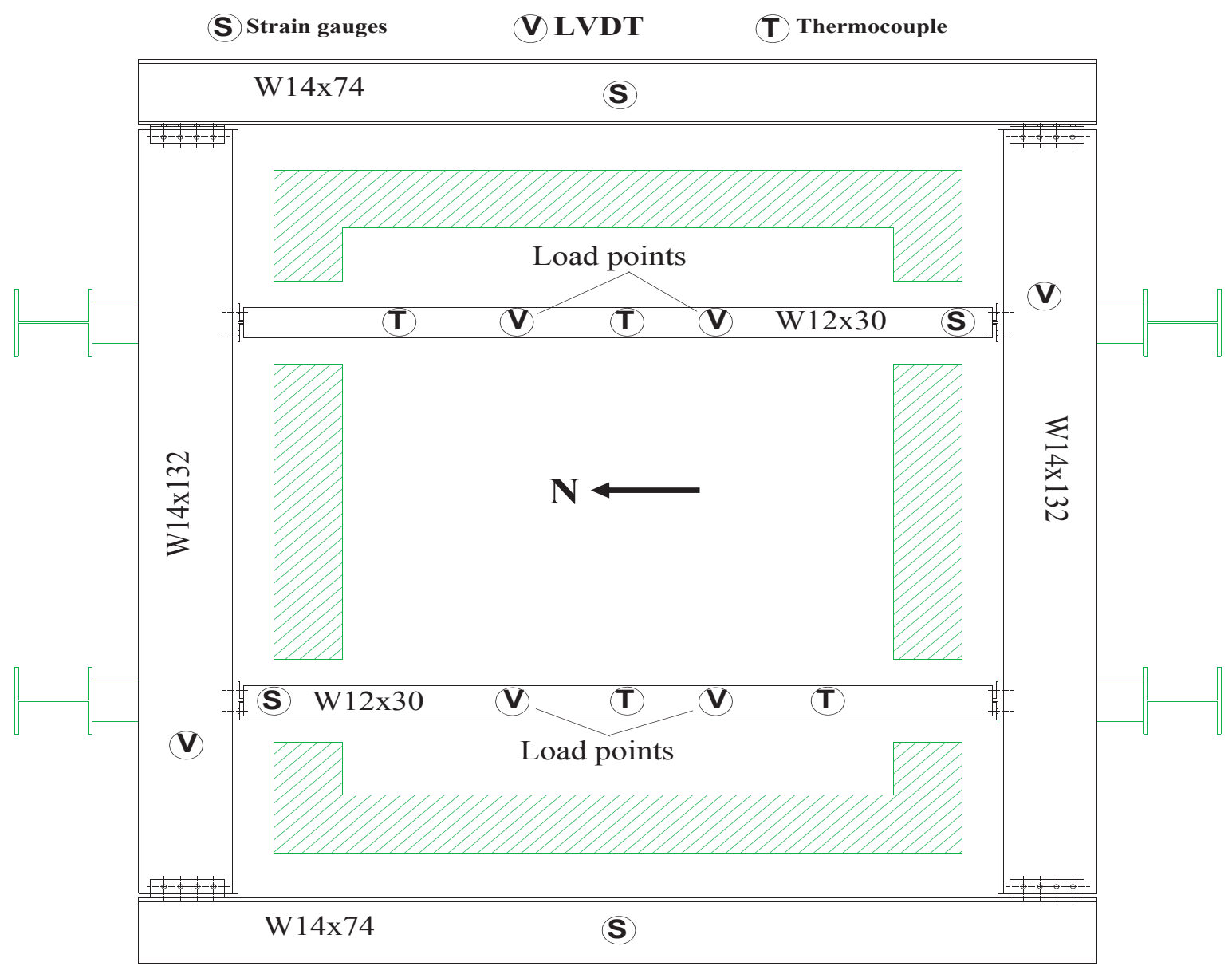

(a) Location of instrumentation, loading in the test assemblies

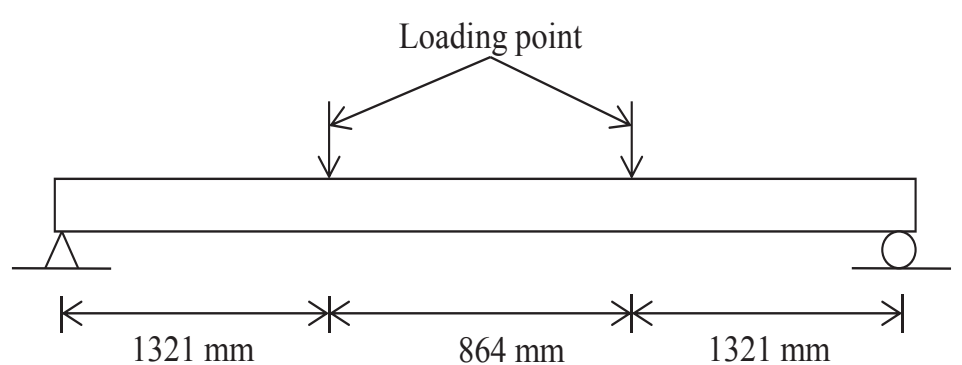

(b) Schematic of load configuration on secondary beam

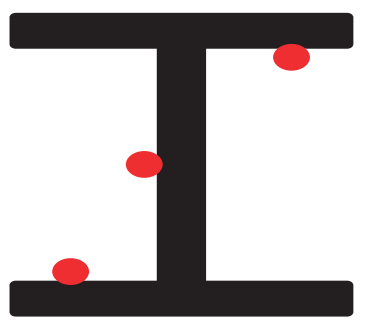

$=$ Thermocouple

(c) Location of thermocouples along The secondary beam cross-section 
Figure 7

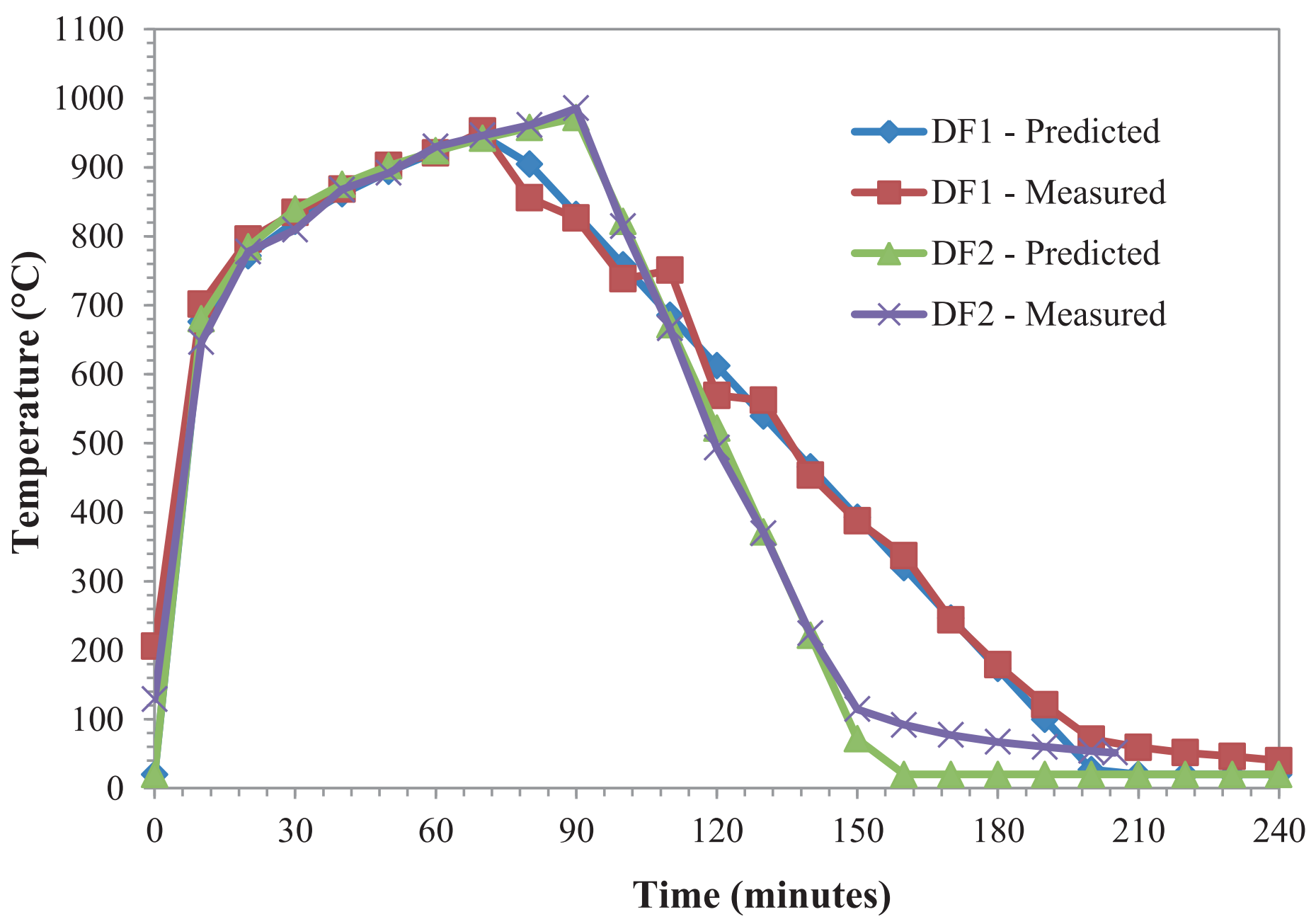


Figure 8

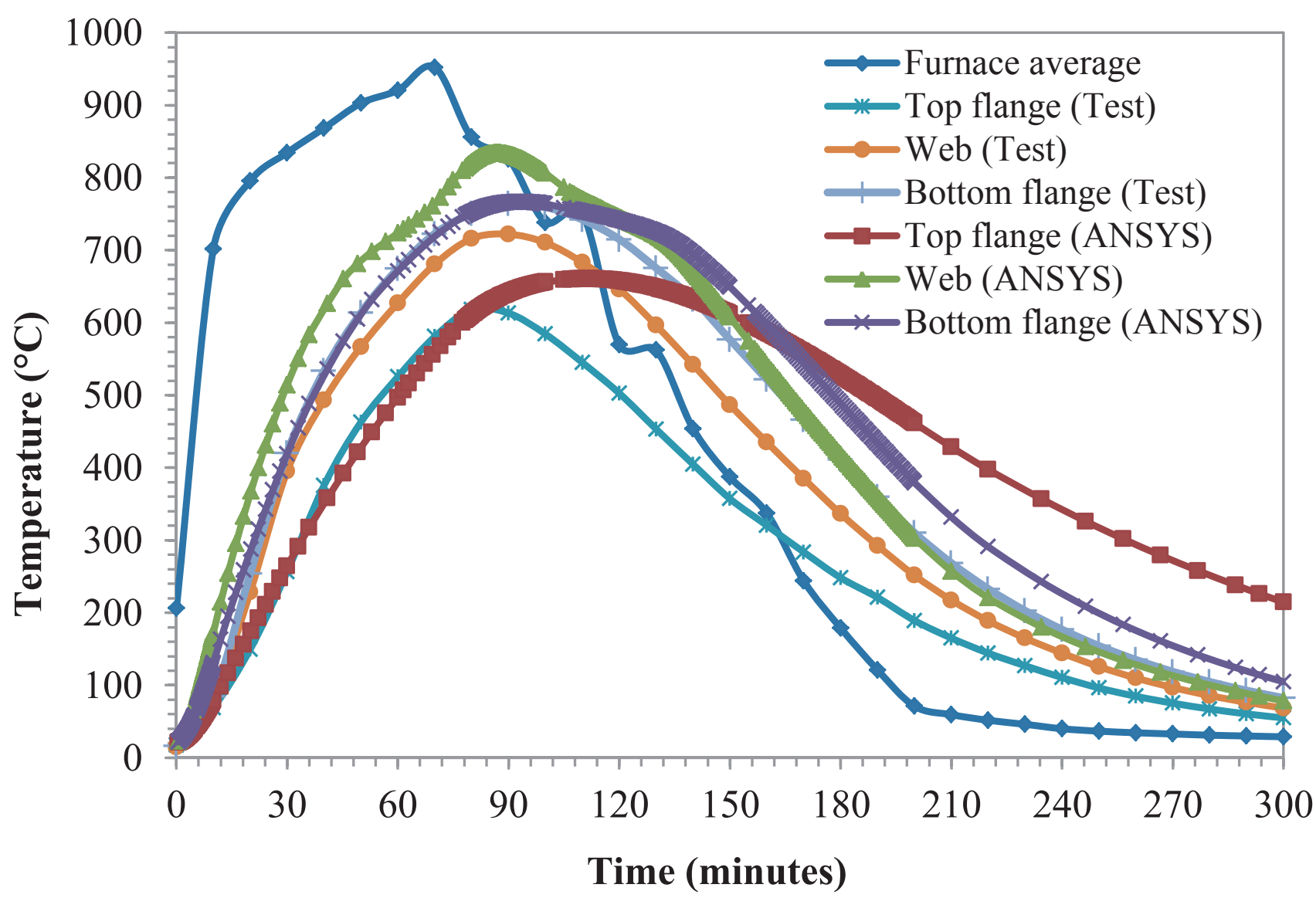

(a) $\mathrm{S} 1$

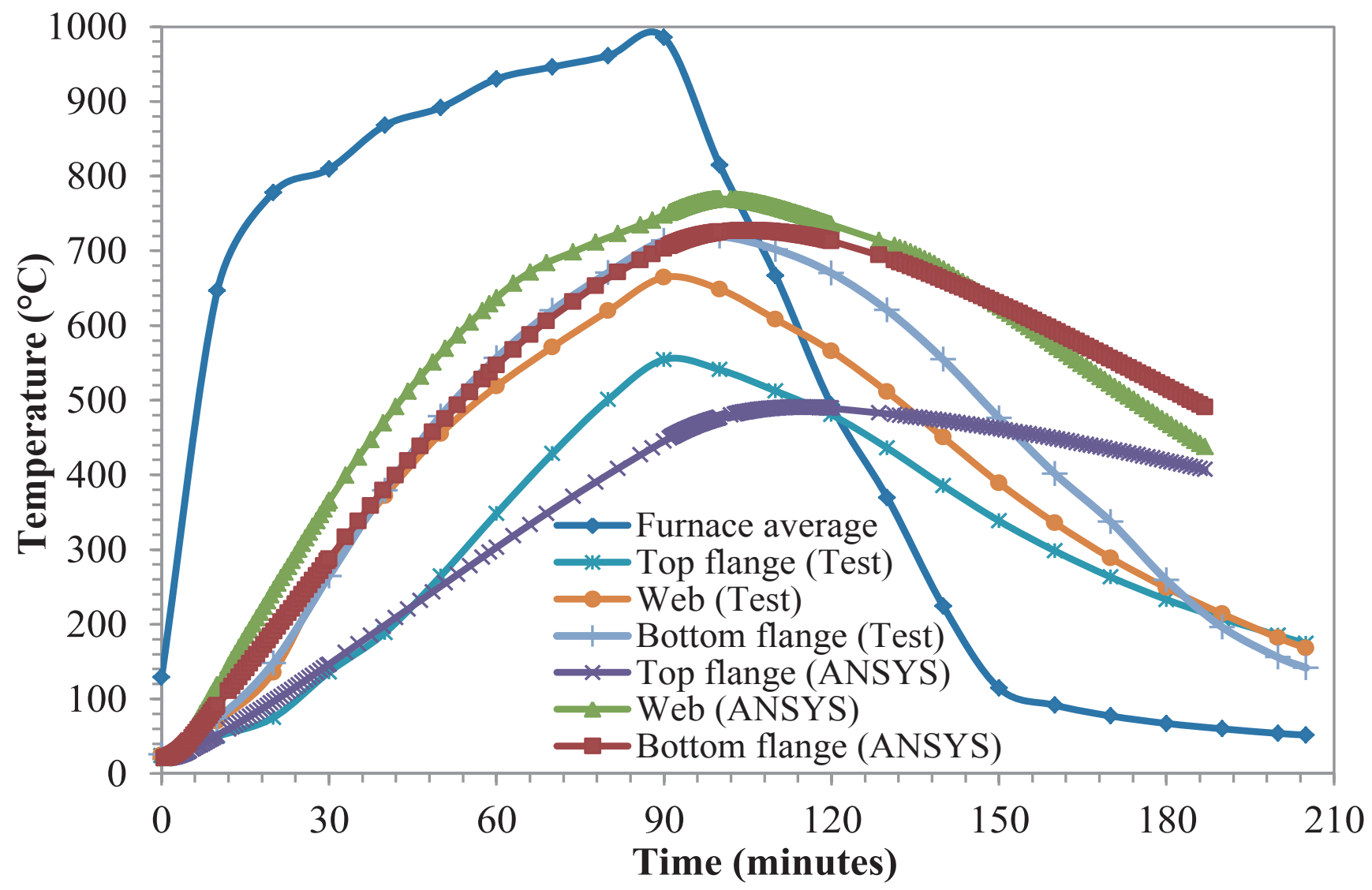

(b) S2 
Figure 9

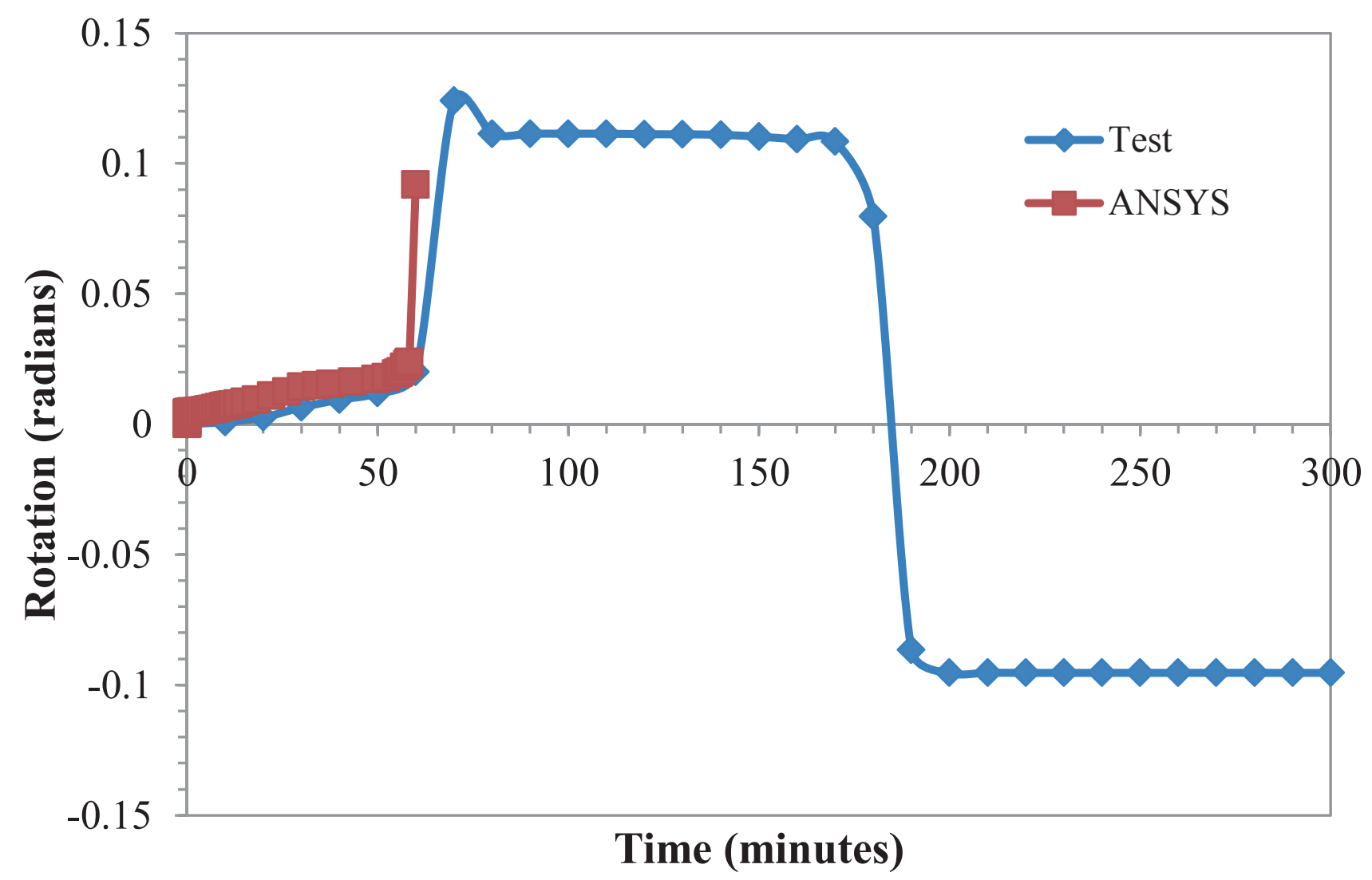

(a) Sub frame assembly $\mathrm{S} 1$

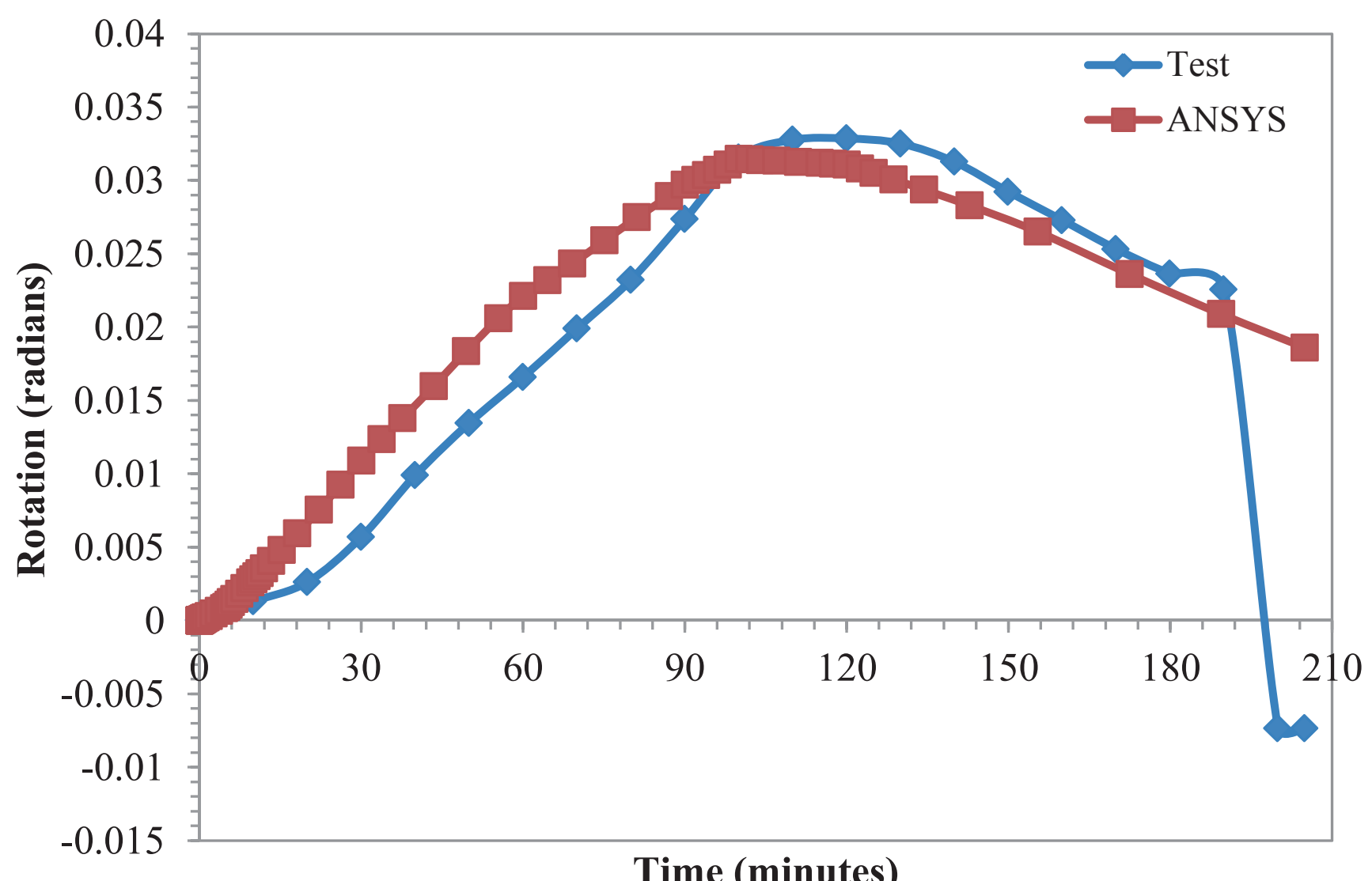

(b) Sub frame assembly S2 


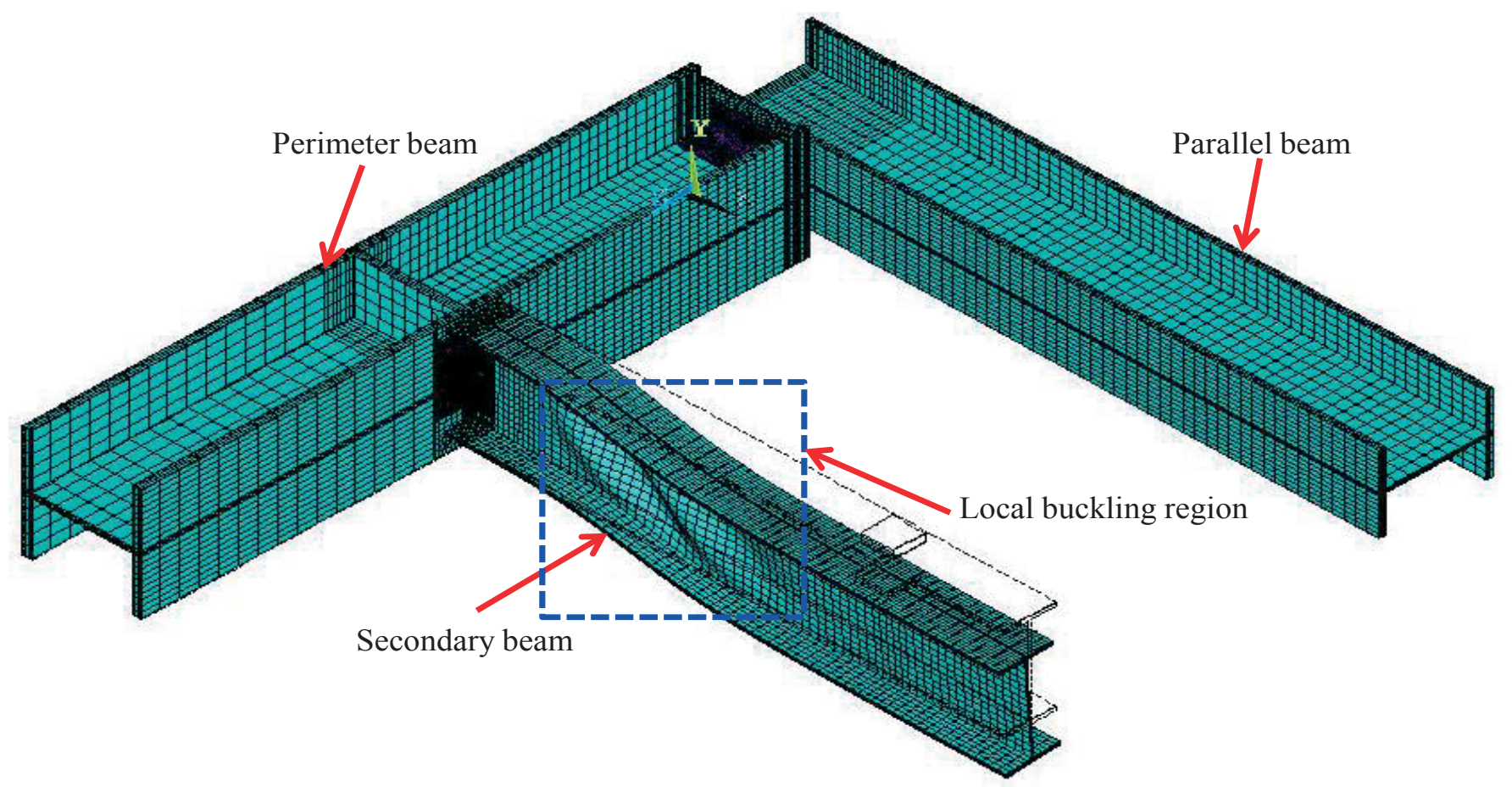

(a) Deformed shape

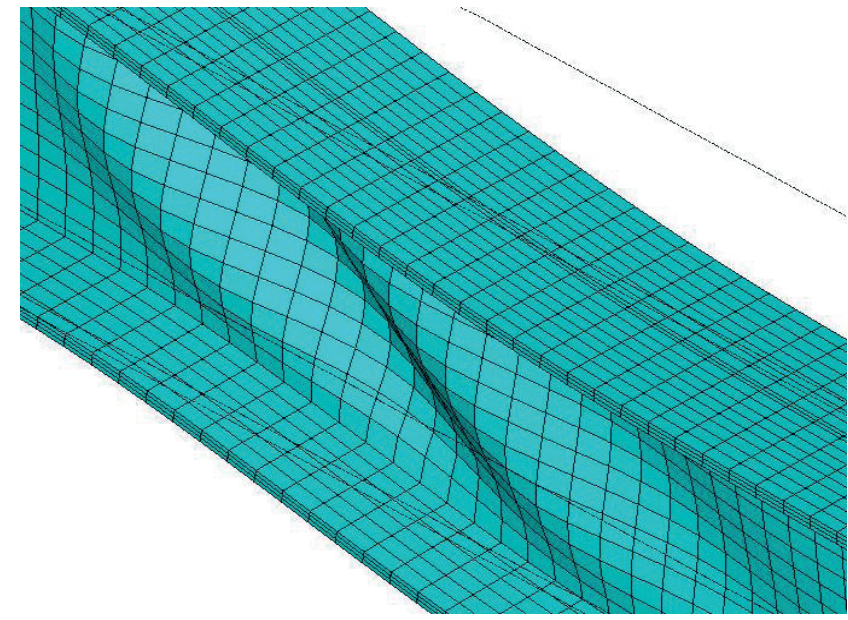

(b) Local buckling

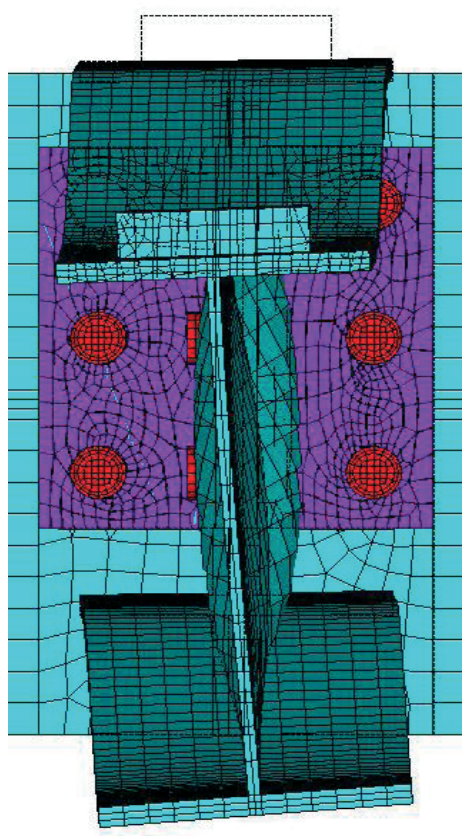

(c) Lateral torsional buckling 
Figure 11
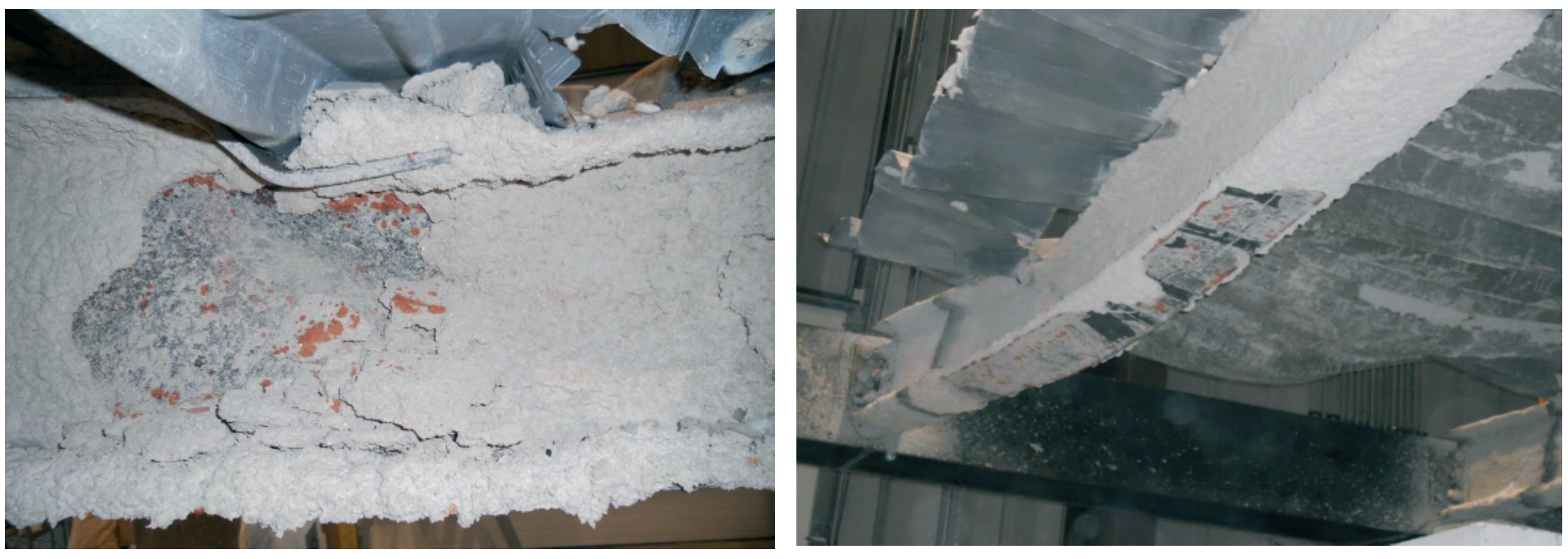
Figure 12

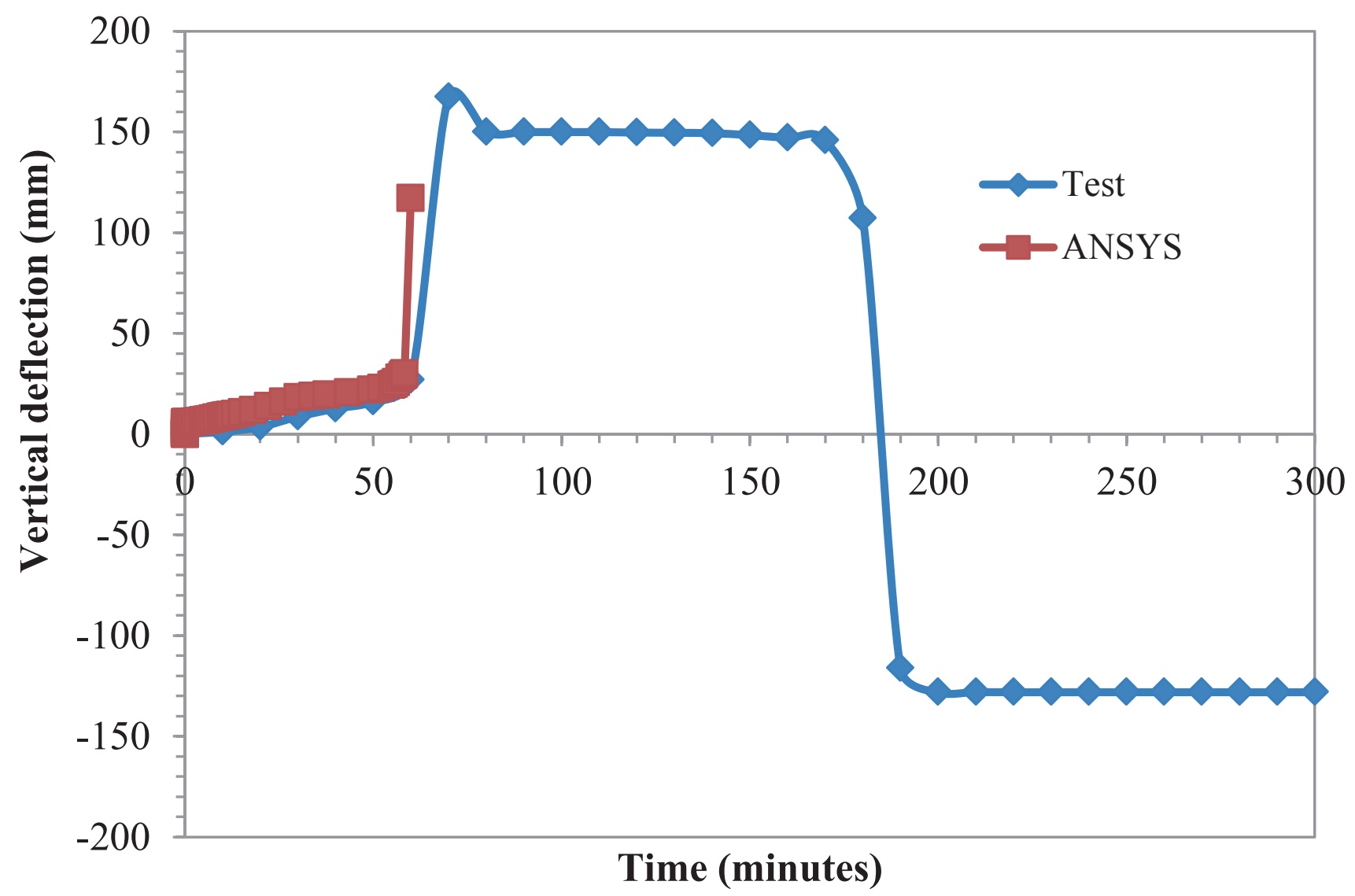

(a) S1

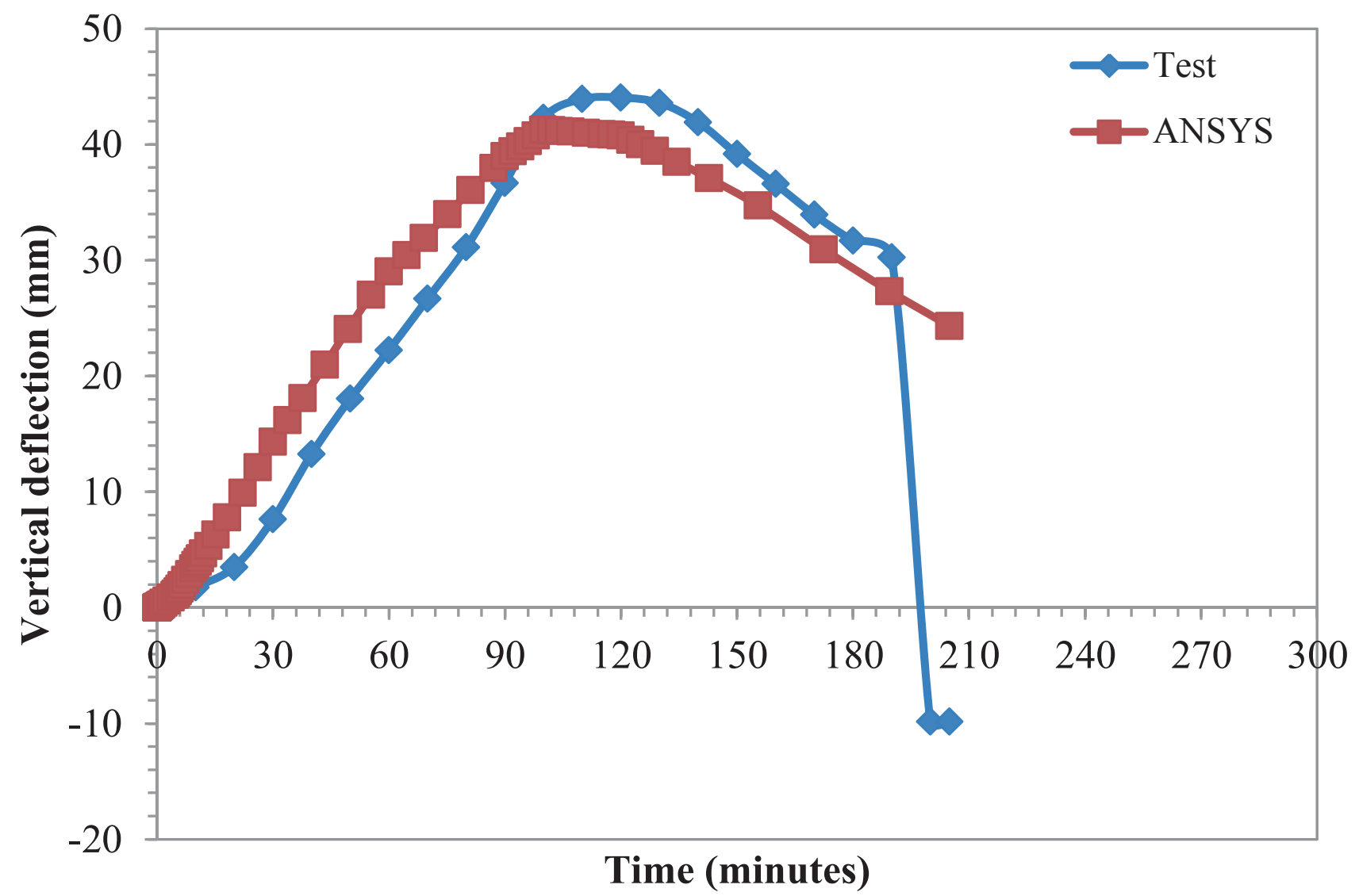

(b) $\mathrm{S} 2$ 
Figure 13

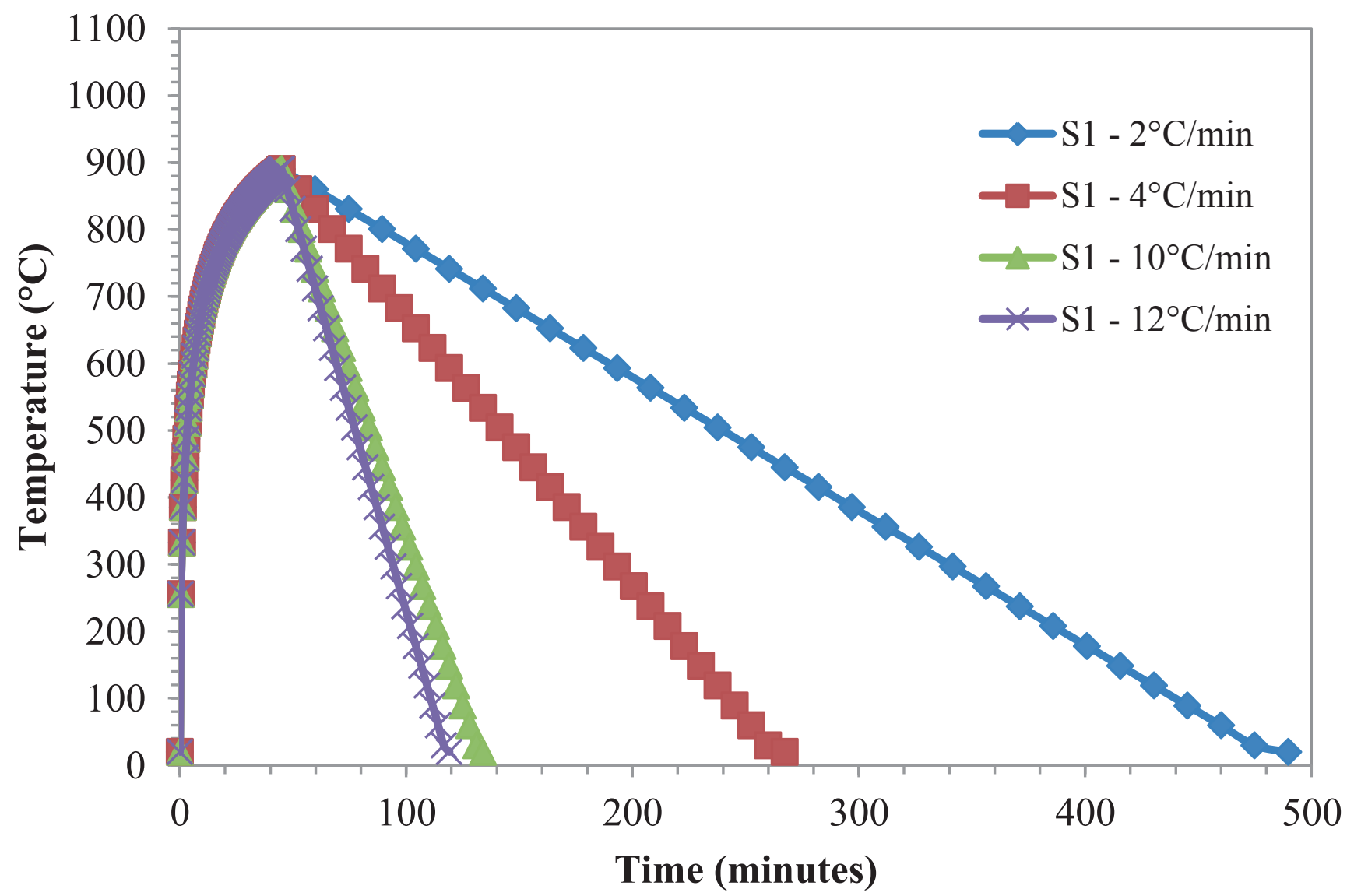

(a) $\mathrm{S} 1$

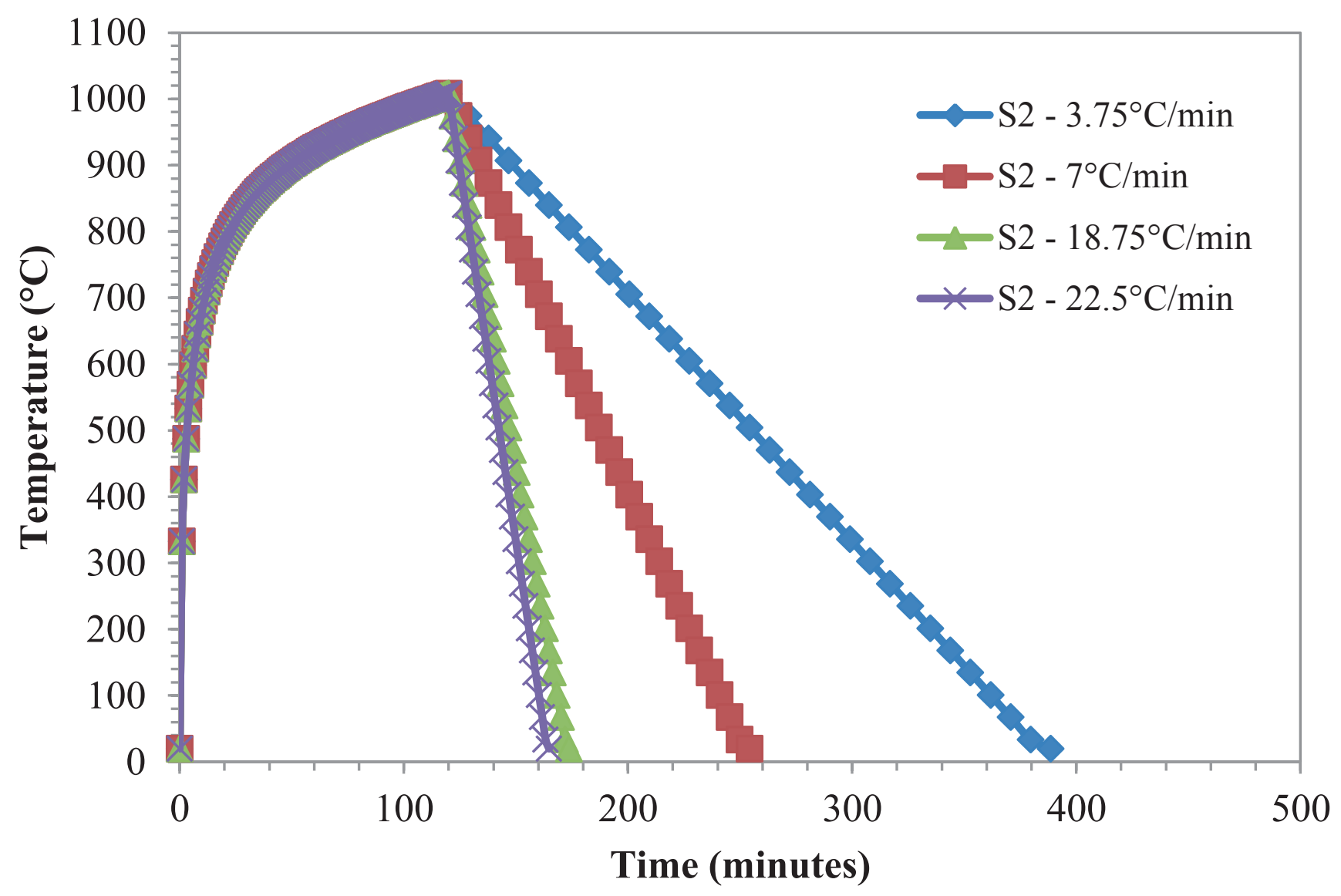

(b) S2 


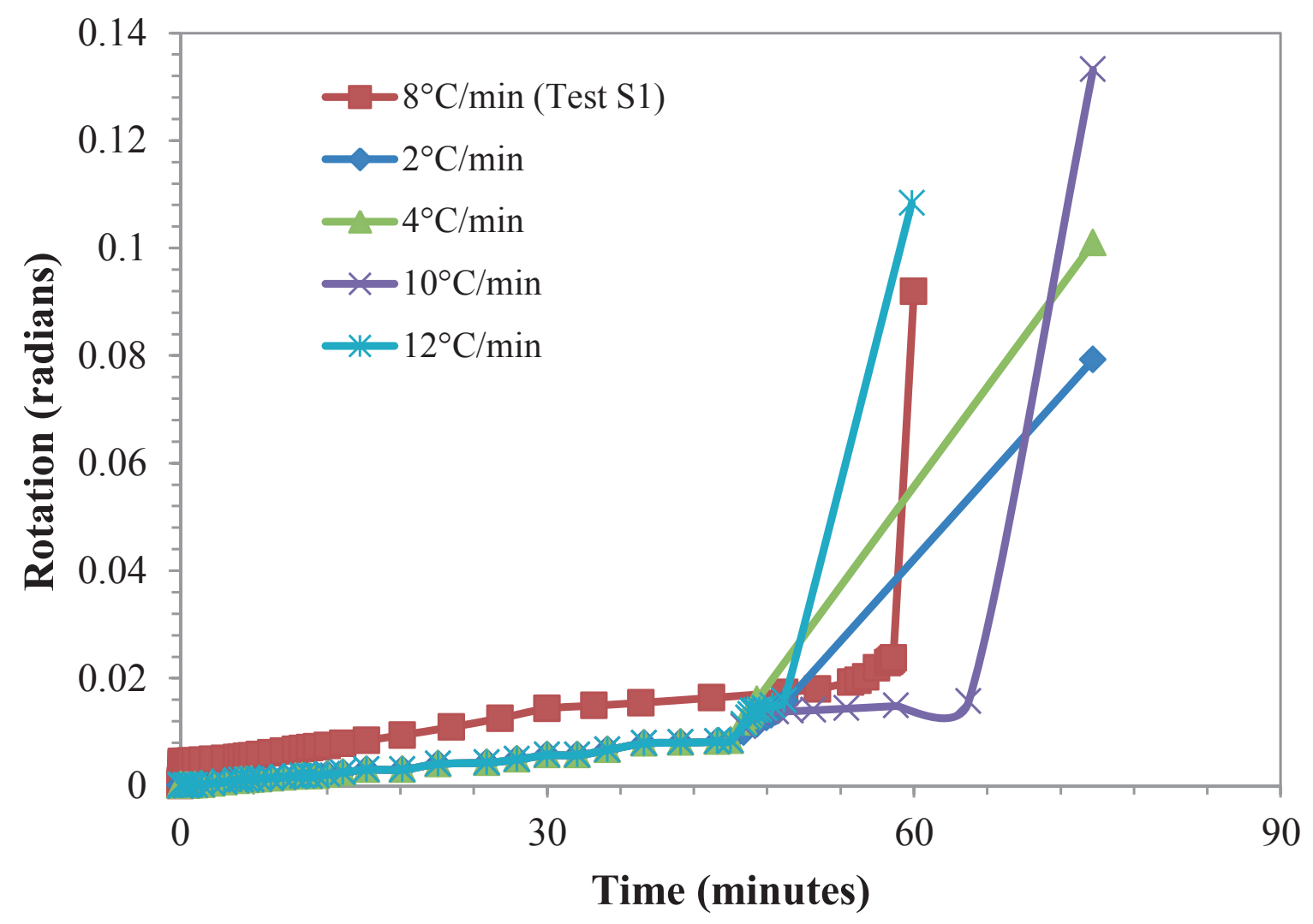

(a) $\mathrm{S} 1$

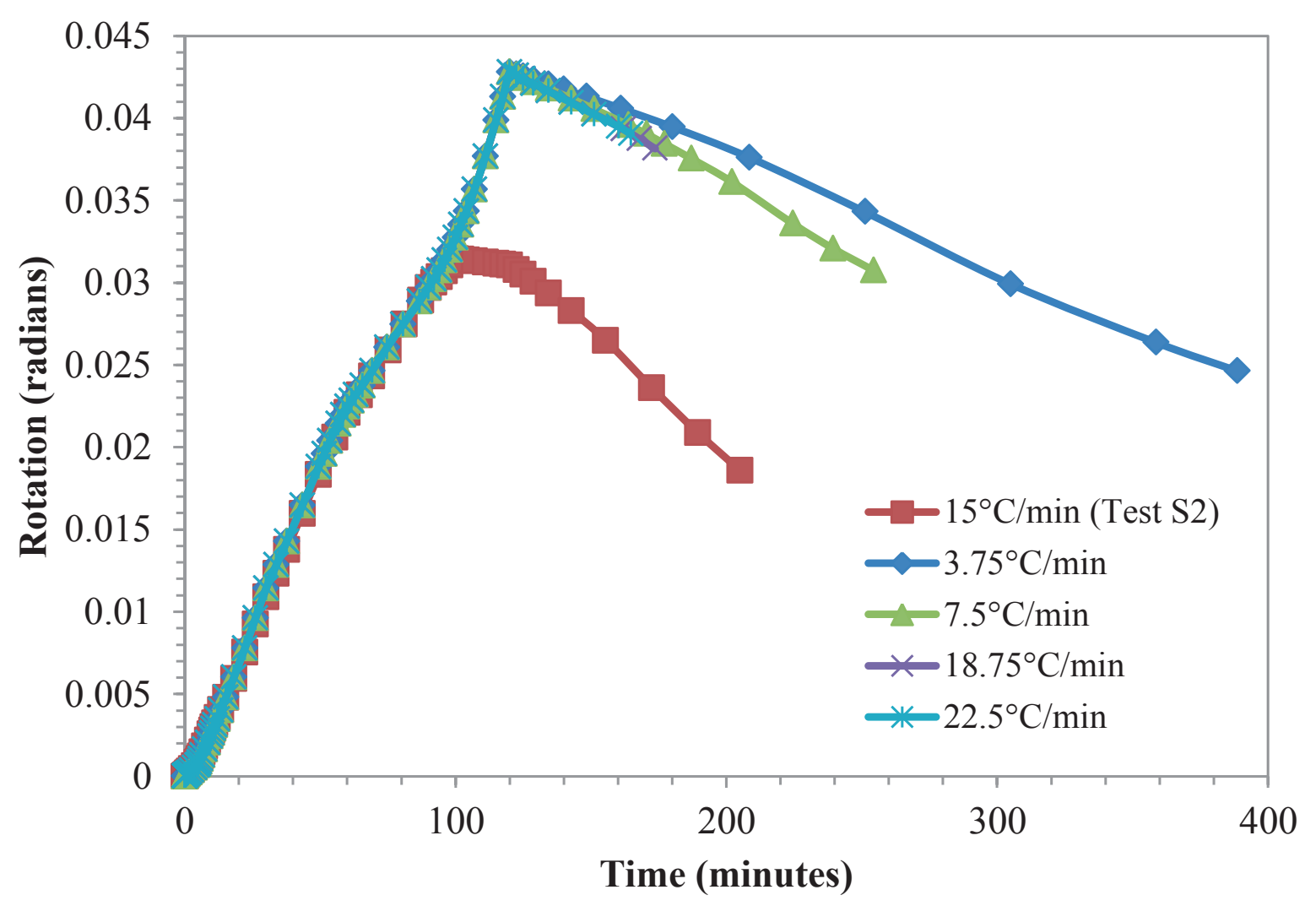

(b) $\mathrm{S} 2$ 
Figure 15

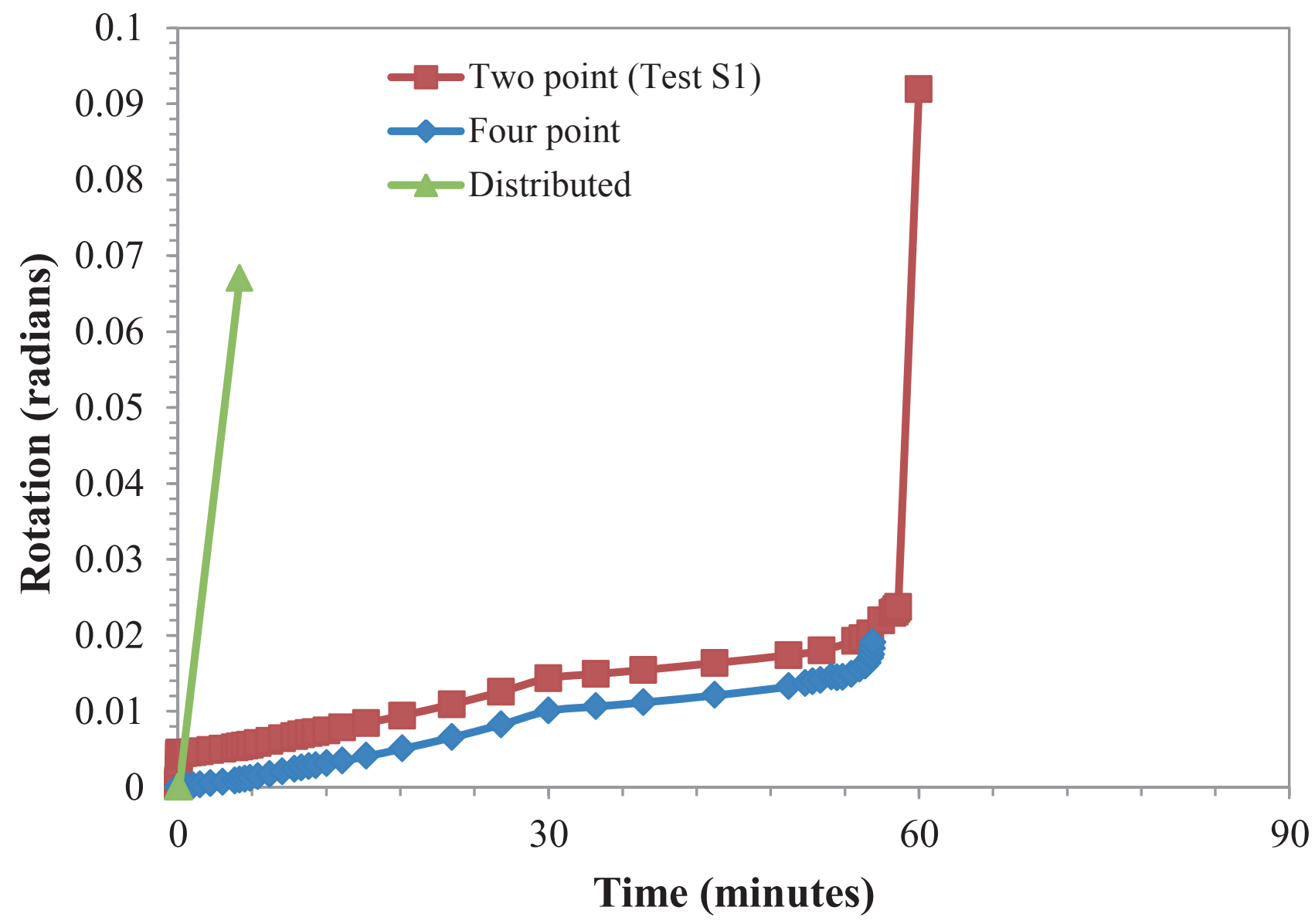

(a) $\mathrm{S} 1$

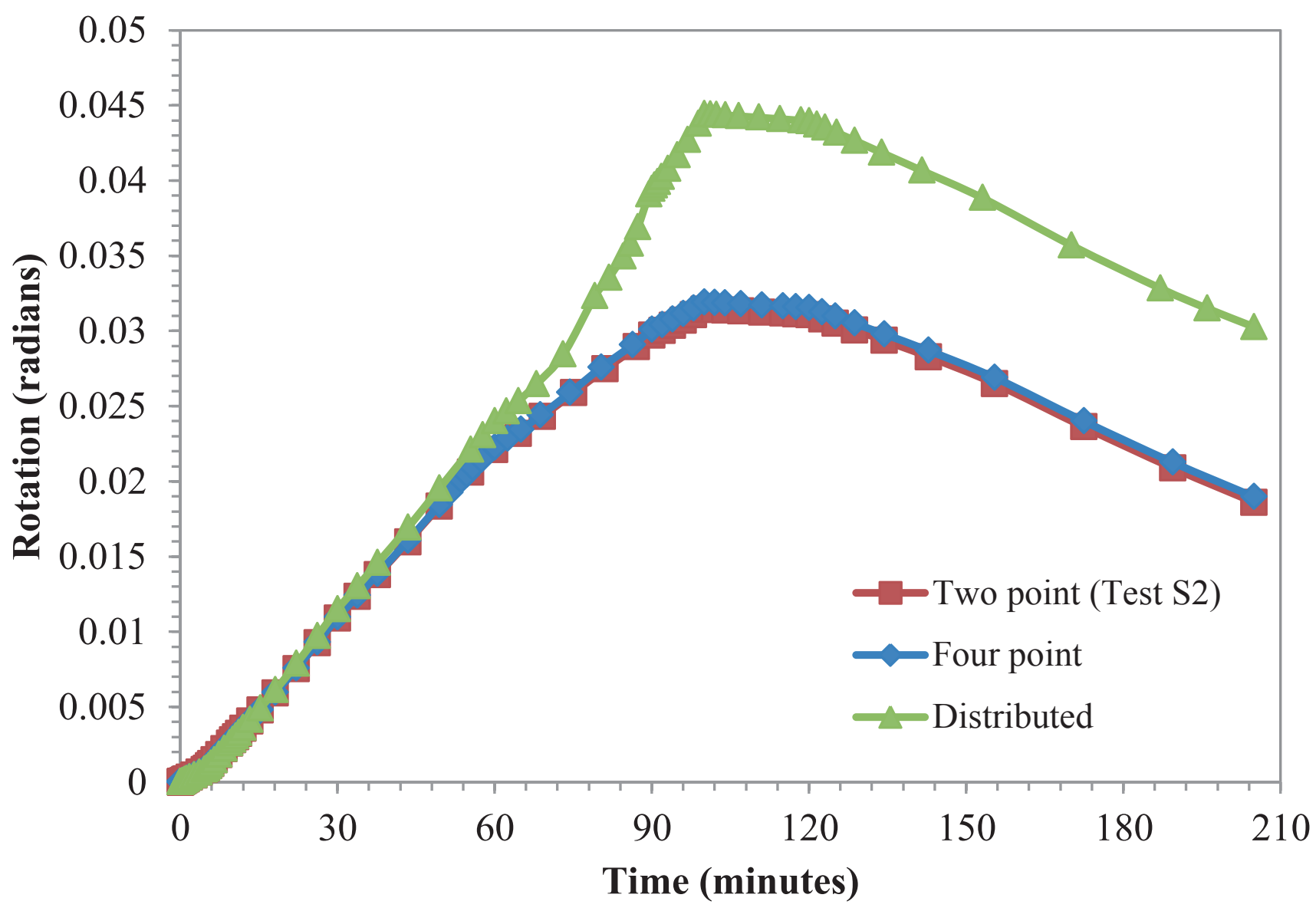

(b) $\mathrm{S} 2$ 
Figure 16

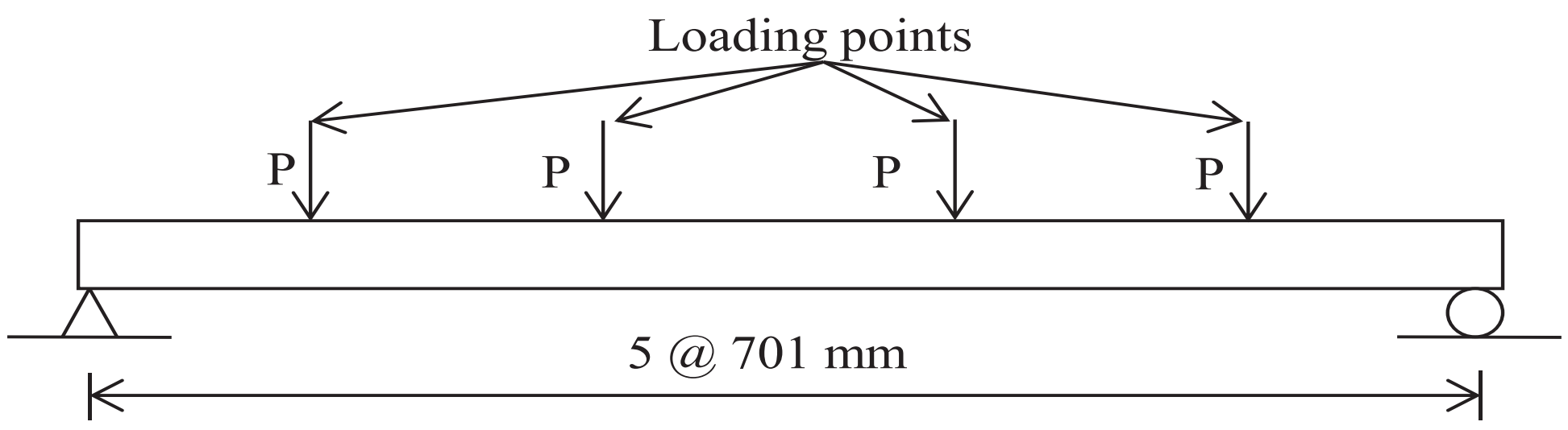

(a) Four point loading

Uniformly distributed load (w/m)

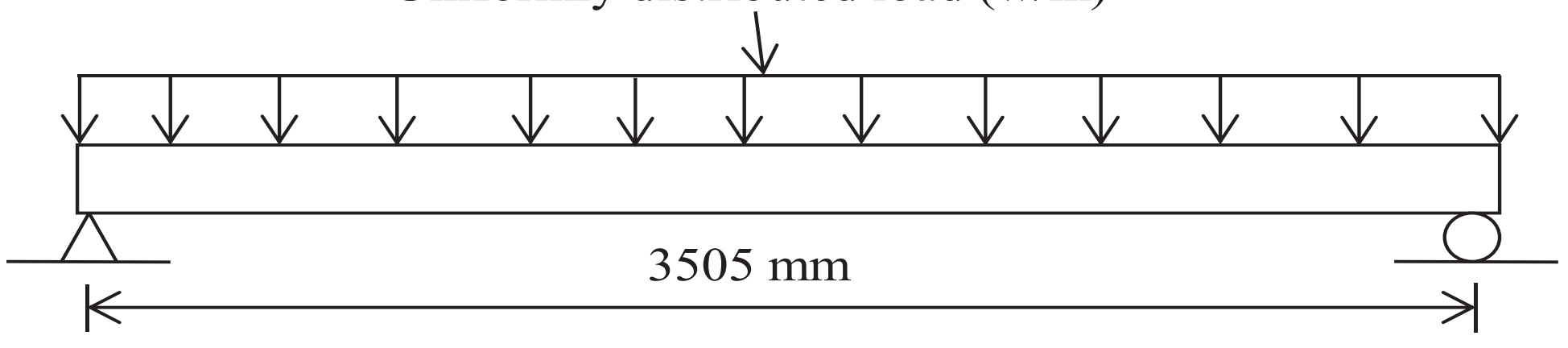

(b) Distributed loading 
Figure 17

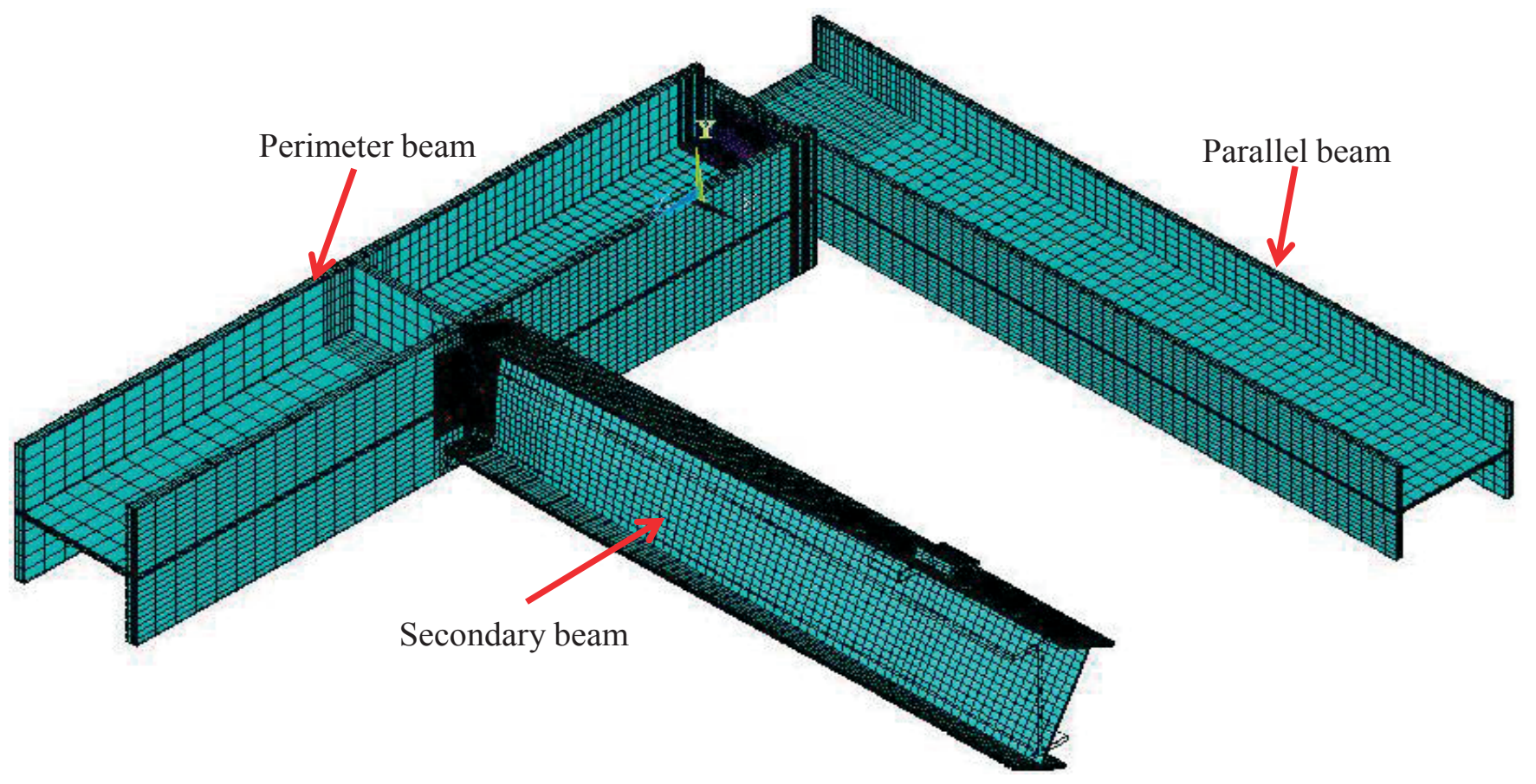

(a) Deformed shape

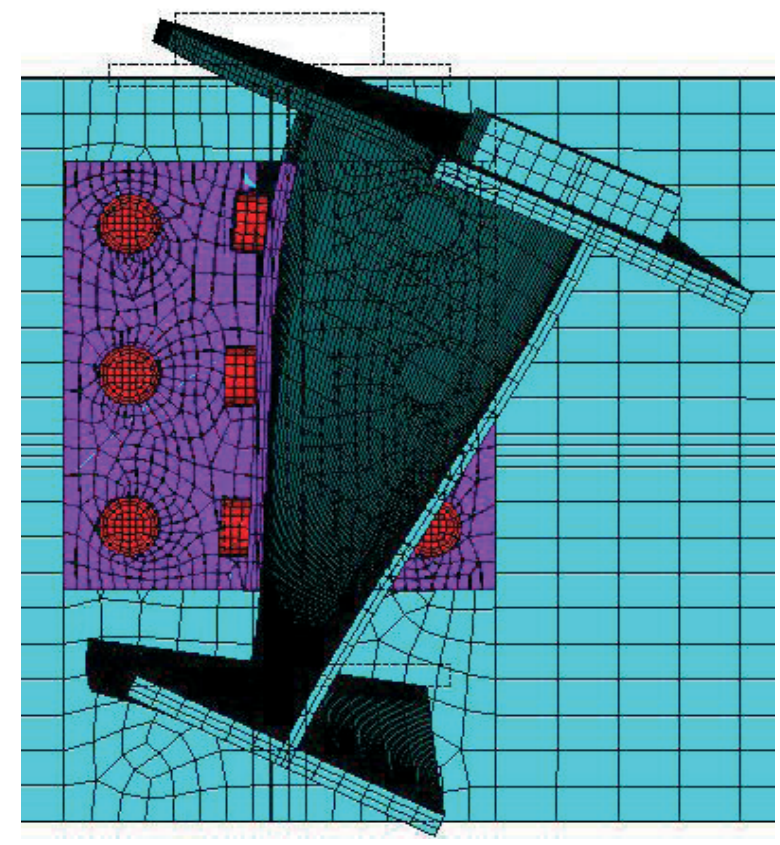

(b) Lateral torsional buckling 
Figure 18

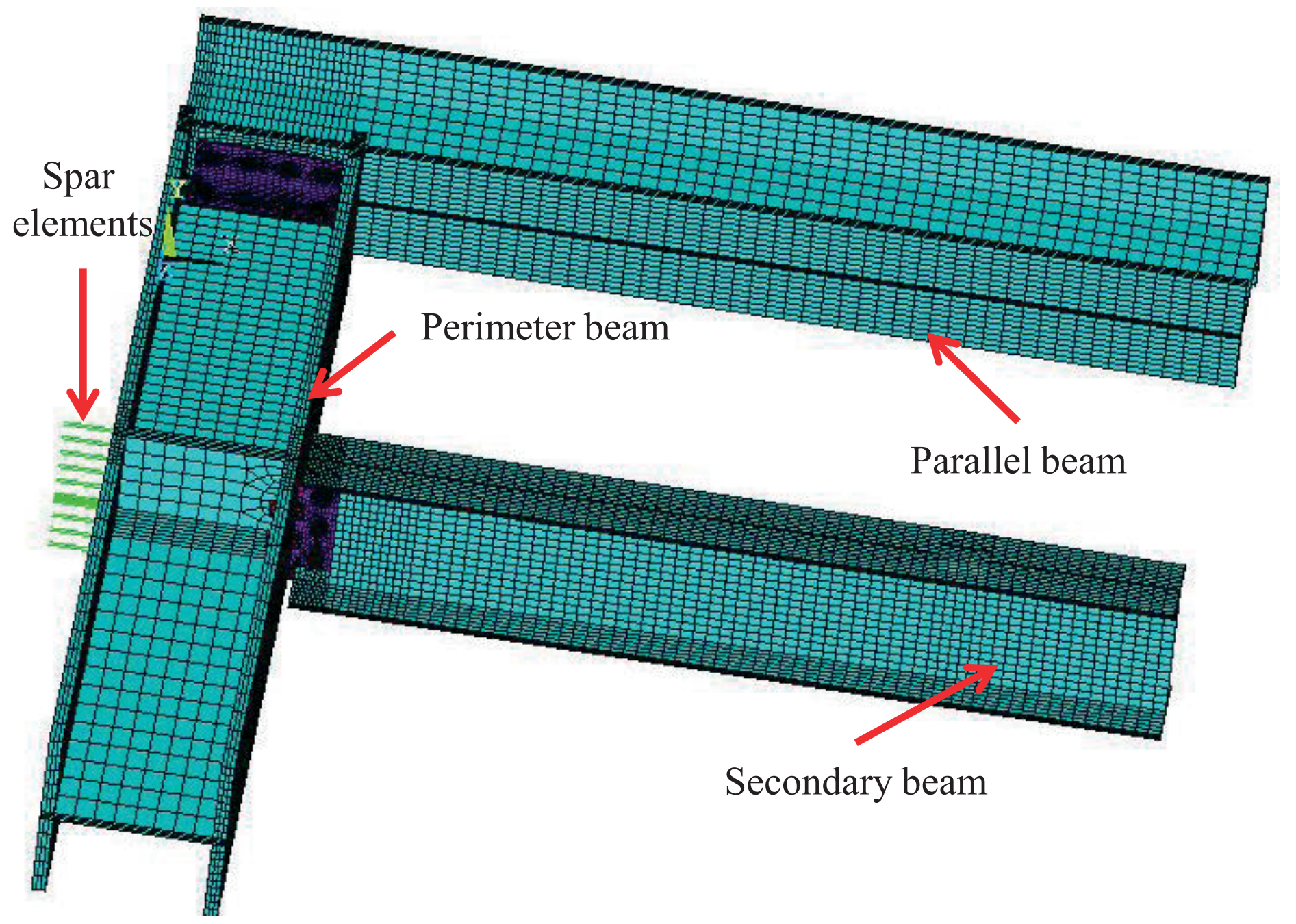


Figure 19

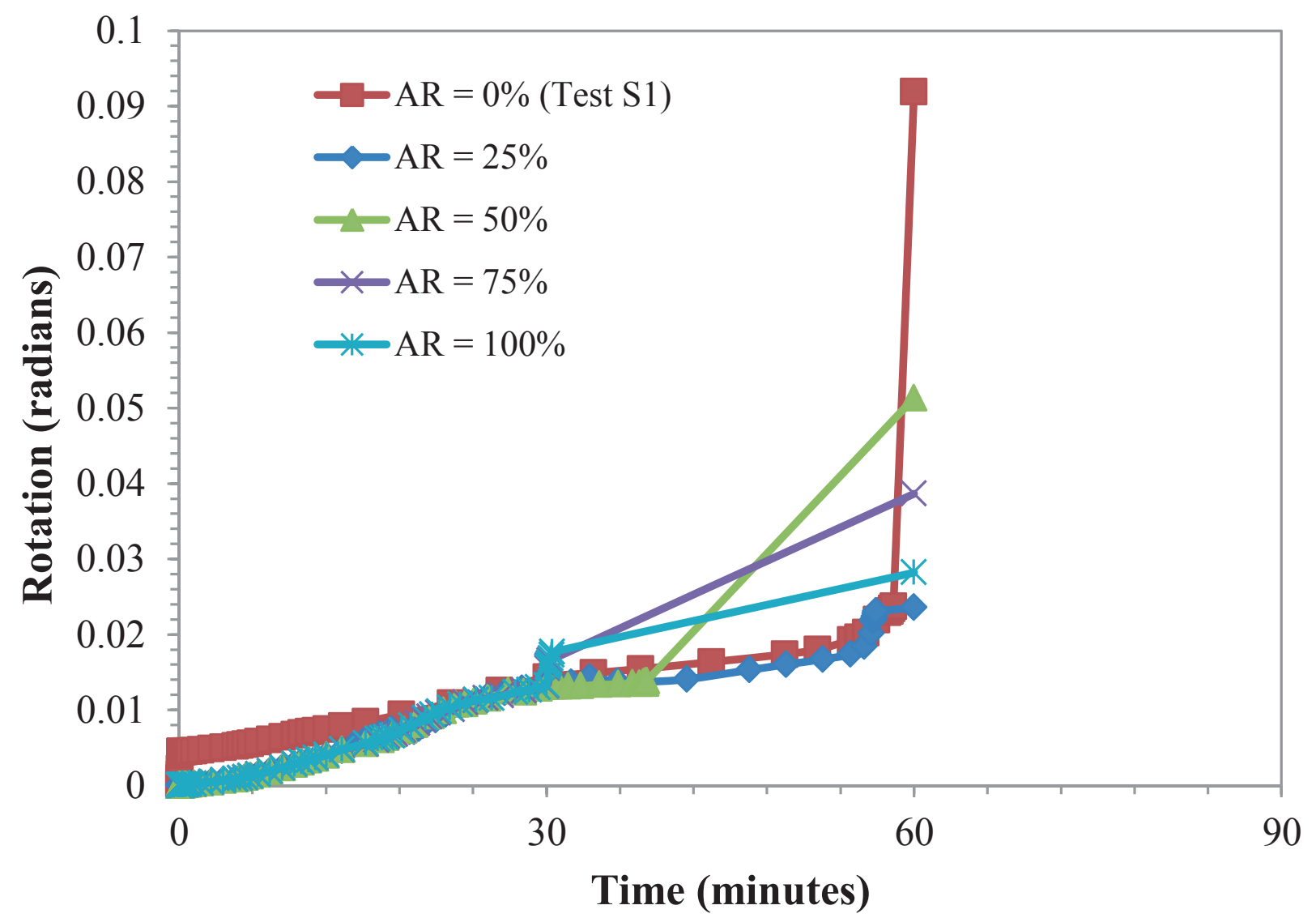

(a) S1

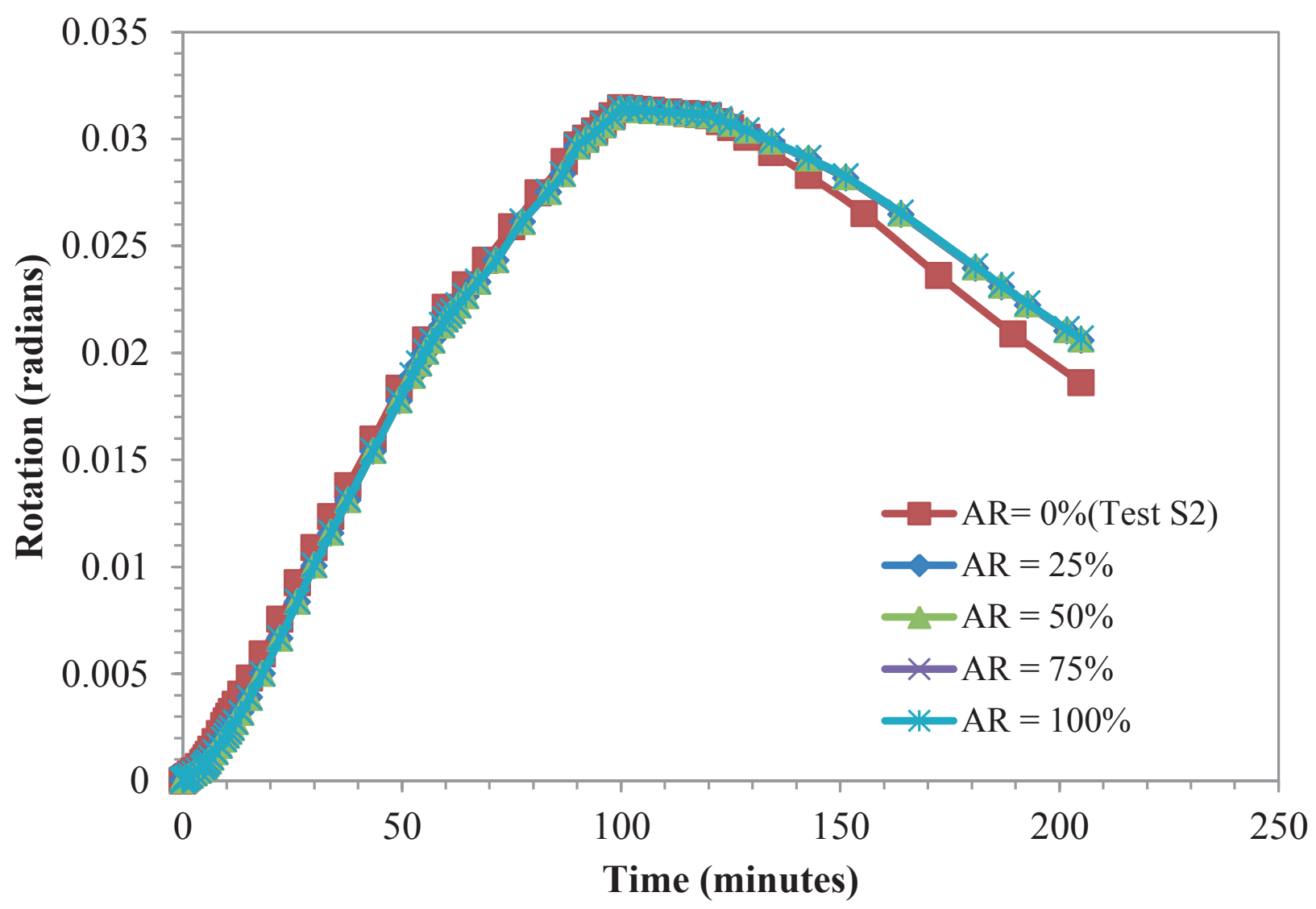

(b) S2 
Figure 20

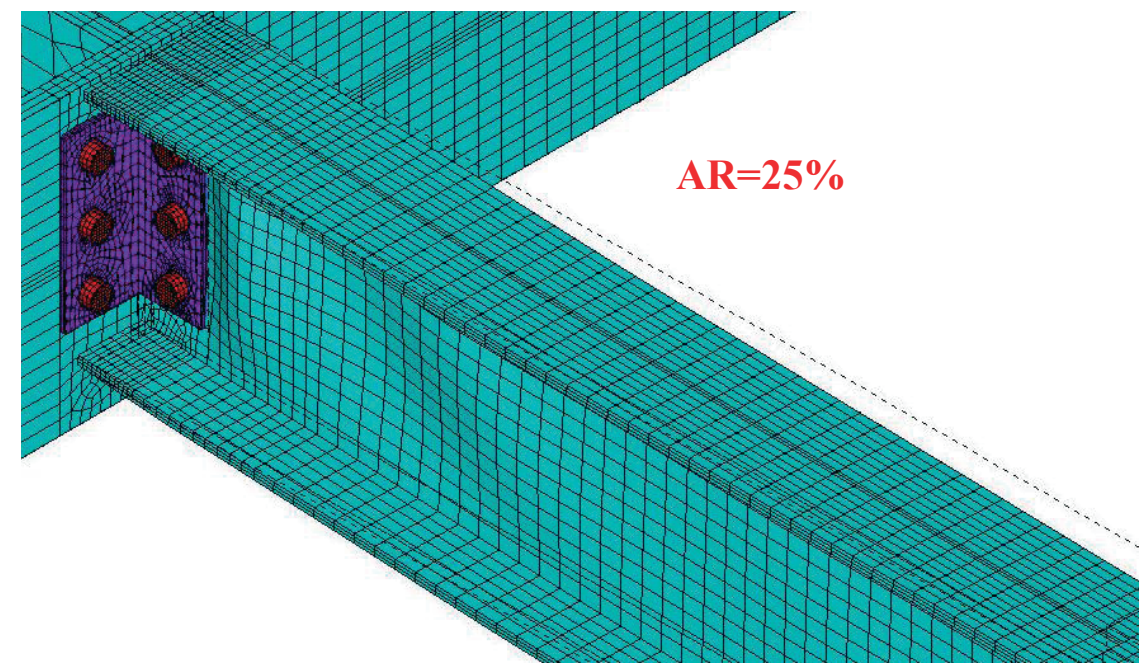

(a) Local buckling

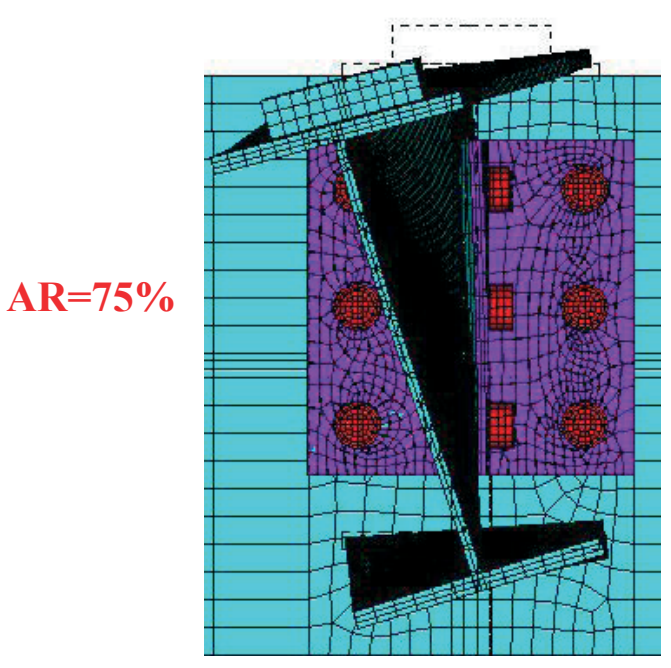

(c) Lateral torsional buckling

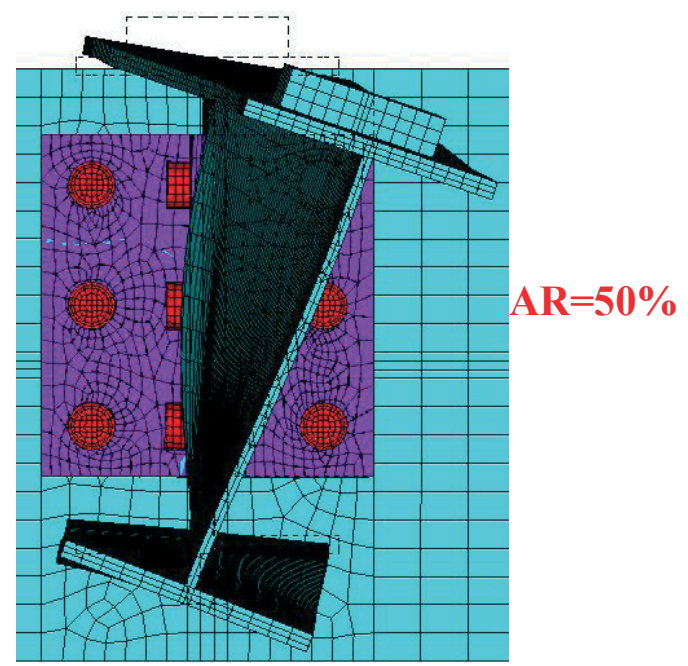

(b) Lateral torsional buckling

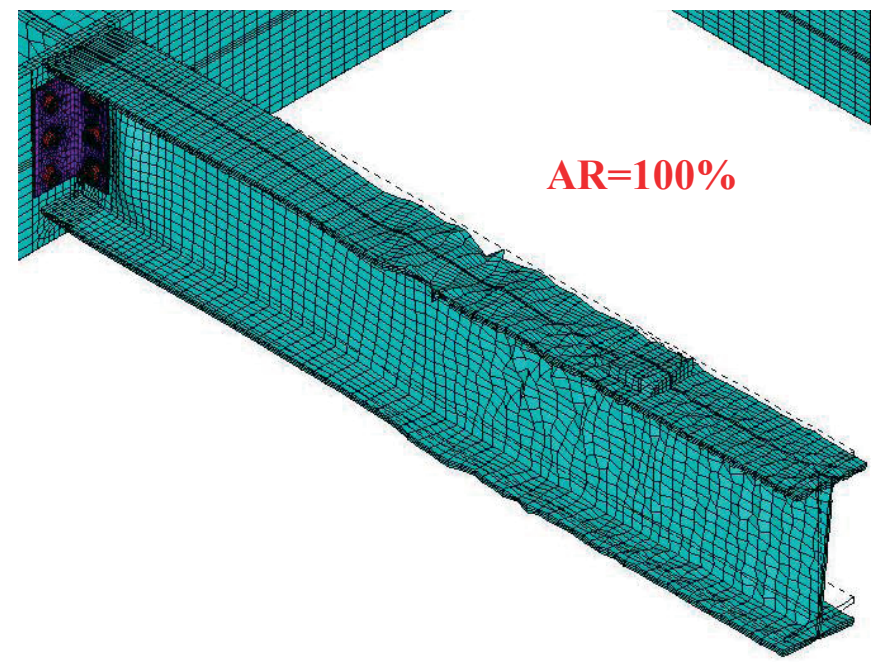

(d) Web and flanges crippling 